\title{
The impact of water supply and sanitation on child health: Evidence from Egypt
}

\author{
Rania Roushdy \\ Population Council \\ Maia Sieverding \\ Population Council \\ Hanan Radwan
}

Follow this and additional works at: https://knowledgecommons.popcouncil.org/departments_sbsr-pgy

Part of the Environmental Public Health Commons, Health Policy Commons, International Public Health Commons, Maternal and Child Health Commons, Medicine and Health Commons, and the Public Health Education and Promotion Commons How does access to this work benefit you? Let us know!

\section{Recommended Citation}

Roushdy, Rania, Maia Sieverding, and Hanan Radwan. 2012. "The impact of water supply and sanitation on child health: Evidence from Egypt," Poverty, Gender, and Youth Working Paper no. 24. New York: Population Council. 


\section{POVERTY, GENDER, \\ AND YOUTH \\ WORKING PAPER}

No. 242012

\section{THE IMPACT OF WATER SUPPLY AND SANITATION ON CHILD HEALTH: EVIDENCE FROM EGYPT}

Rania Roushdy, Maia Sieverding, and Hanan Radwan 


\section{(2) Population Council}

One Dag Hammarskjold Plaza

New York, New York 10017 USA

www.popcouncil.org

The Population Council confronts critical health and development issues-from stopping the spread of HIV to improving reproductive health and ensuring that young people lead full and productive lives. Through biomedical, social science, and public health research in 50 countries, we work with our partners to deliver solutions that lead to more effective policies, programs, and technologies that improve lives around the world. Established in 1952 and headquartered in New York, the Council is a nongovernmental, nonprofit organization governed by an international board of trustees.

For information on Poverty, Gender, and Youth working papers, see

www.popcouncil.org/publications/wp.asp

This material may not be reproduced without written permission from the Population Council.

ISSN: $1554-8538$

(c) 2012 The Population Council, Inc. 


\title{
The Impact of Water Supply and Sanitation on Child Health: Evidence from Egypt
}

\author{
Rania Roushdy \\ Maia Sieverding \\ Hanan Radwan
}

Rania Roushdy is a Senior Program Manager, Poverty, Gender, and Youth Program, Population Council, Egypt Office. Maia Sieverding is a Program Officer, Poverty, Gender, and Youth Program, Population Council, Egypt Office, and a Ph.D. Candidate, Sociology and Demography, University of California Berkeley. Hanan Radwan is a freelance consultant. This research was conducted as part of a multicountry project funded by the International Initiative for Impact Evaluation (3ie). The views expressed in this report are those of the authors and do not necessarily reflect those of 3ie. 


\begin{abstract}
Using a combination of qualitative and quantitative data, this paper investigates whether access to improved sources of water and sanitation is an effective "treatment" for the incidence of diarrhea among children under five years of age in Egypt. The qualitative component of the paper draws on in-depth interviews and focus group discussions with residents of three governorates to present an account of Egypt's drinking water and sanitation services. The quantitative analysis then uses 2008 Egypt Demographic and Health Survey data to investigate the insights obtained from the qualitative research conducted on a large nationally representative sample. Both the quantitative and qualitative components of the study indicate that widespread access to improved sources of drinking water and toilet facilities exists across Egypt; however, service quality remains a significant problem in many areas. In particular, cuts in water supplyand the resulting practice of storing water-are quite common. A sizable percentage of flush toilet facilities are not connected to the public sewer system, and evacuation and disposal services for septic tanks are inadequate. Quantitative analysis, using propensity score matching techniques, indicates that having an uninterrupted water supply has a significant negative effect on the incidence of childhood diarrhea. Nevertheless, having a flush toilet facility connected to the sewer system is found to have a positive effect on the incidence of childhood diarrhea, leading us to conclude that there are other important measures of service quality not captured by the survey data used.
\end{abstract}


This study investigates the relationship between child health in Egypt and the availability of improved drinking water and sanitation services, with a particular focus on diarrhea as a major disease affecting health status and mortality among children. Using a combination of qualitative and quantitative data, the study's main objective is to determine whether access to improved sources of water and sanitation in Egypt is an effective "treatment" for the incidence of diarrhea among children who are less than five years of age. Potential mechanisms behind the relationships between child health and different types of water supply and sanitation (WSS) services are also explored.

Diseases, including childhood diarrhea, are often caused by a multitude of factors. Numerous studies have revealed a strong connection between childhood diarrhea and the quality and use of water and sanitation services. According to the World Health Organization (WHO) and the United Nations Children's Fund (UNICEF), an estimated 88 percent of diarrheal deaths worldwide are attributable to unsafe water, inadequate sanitation, and poor hygiene, indicating that WSS interventions can play an important role in combating the incidence of this disease among children. These interventions may include improving access to safe water, improving water quality at the source, treating household water and storing it safely, improving access to adequate sanitation facilities, and encouraging good hygiene practices, particularly hand washing (WHO/UNICEF 2004). Recent reviews of impact evaluation literature (Pattanayak et al. 2007; World Bank 2008; Waddington et al. 2009) reveal, however, that the evidence base regarding WSS interventions, especially with regard to sanitation, is extremely weak. Accordingly, this study aims to fill that gap.

The qualitative component of the paper draws on in-depth interviews and focus group discussions with residents of three governorates to present an account of Egypt's drinking water and sanitation services as well as the use of those services by households and other institutions frequented by children (notably schools and local public health clinics), before and after piped water and wastewater networks were introduced. The quantitative analysis then investigates the insights that were obtained from the qualitative research on a large sample. The $2008 \mathrm{Egypt}$ Demographic and Health Survey (2008 EDHS) is used to investigate the effects on childhood diarrhea of uninterrupted access to a piped source of drinking water inside or outside the household, and of having access to a flush toilet connected to a public sewer. Since access to improved services is highly conditioned on household socioeconomic status and region of residence, we use propensity score matching (PSM) techniques to match children who have access to improved services (treatment group) with children in a comparison group who do not have access to such improved services. We control for several observable community and household characteristics that may be correlated with both child health and WSS to reduce the possibility of this selection-bias problem. We draw on the insights of the qualitative data to examine the impact of several different definitions of improved water and sanitation services.

Both the quantitative and qualitative components of the study indicate that widespread access to improved water supply and sanitation exists in Egypt, according to standard WHO definitions. Access to improved WSS services has increased over the past 15 years and is now 
close to universal. Service quality remains a significant problem in many areas, however. In particular, cuts in water supply - and the resulting practice of storing water-are common. A sizable percentage of flush-toilet facilities are not connected to the public sewer system, and evacuation and disposal services for septic tanks are inadequate. Quantitative analysis indicates that having an improved and uninterrupted water supply has a significant negative effect on the incidence of childhood diarrhea, compared with having unimproved or improved but interrupted service. Having an improved toilet facility connected to the sewer system is, however, found to have a positive effect on the incidence of childhood diarrhea, leading us to conclude that there are other important measures of service quality not captured by the survey data used.

Overall, the results of the study indicate that current survey data on WSS services is not adequate to address the wide range of service-quality issues experienced by Egyptian households. At least one such quality issue - the consistent supply of piped water-is shown to have a significant negative impact on the prevalence of childhood diarrhea, which constitutes a major obstacle to identifying the effect of WSS on child health. New surveys that collect detailed data on quality-of-service issues at both the household and neighborhood levels are needed.

This report is organized into seven sections: Introduction, History of WSS Service Provision in Egypt, Literature Review, Methodology, Water and Sanitation Service Delivery in Egypt, Effect of Improved WSS Services on Childhood Diarrhea, and Conclusion and Recommendations.

\section{History OF WSS Service Provision in EgyPT}

\section{WSS services before privatization}

The provision of water and sanitation services in Egypt has always been viewed as a government responsibility. ${ }^{1}$ Until recently, construction, treatment, and rehabilitation of water and sanitation services was controlled and managed by the government through the National Organization for Potable Water and Sanitary Drainage (NOPWASD). This situation continues to exist in one of the study governorates, Qaliubeya. Falling under the Ministry of Housing and Urban Utilities Development (MHUUD), NOPWASD also was, and continues to be, responsible for construction and rehabilitation of large drinking-water supply and sanitation-treatment plants, lifting/pump stations, main pipe networks, and other operations requiring large-scale tendering. These operations are financed by the government, which channels the funds through the Ministry of Finance. The broader environmental health factors associated with the impact of water and sanitation programs are the responsibility of the Ministry of Health and Population.

Until recently, the Operation and Maintenance $(\mathrm{O} \& \mathrm{M})$ of drinking water and sanitation

services was the mandate of MHUUD branches at the local government level. ${ }^{2}$ Financed by the central investment budget, channeled through the Ministry of Finance, the O\&M plan was decided at MHUUD headquarters in Cairo and communicated and implemented through its regional offices at the governorate, district, and local unit levels. Technically, officials and staff 
in these offices were answerable to the MHUUD and its national five-year plan, while administrative issues were the prerogative of the governor and local government departments.

Even prior to privatization, however, the Government of Egypt (GOE) was not the sole, or even the primary, WSS service provider. From 1975 to the early 1990s, the contribution of the United States Agency for Aid and International Development (USAID) to WSS projects in Egypt was substantial, with more than US $\$ 3.4$ billion invested in 13 water and wastewater projects. The execution of these projects was based on a bottom-up participatory approach where project plans were developed from the village level upward and financed exclusively by USAID (USAID 2006).

This bottom-up approach has been adopted by the government-financed and -managed Shrouk program, which took over infrastructure investment after the decline of USAID participation in that sector. Falling under the Ministry of Local Development, the Shrouk program continues to finance infrastructure projects such as roads, water, and sanitation in rural regions, albeit on a smaller scale because of limited government resources and the takeover of O\&M of water and sanitation services by private companies. Other donors, such as the Social Fund for Development (SFD), ${ }^{3}$ CARE, and the German Agency for Technical Cooperation (GTZ) have also been involved in the expansion and rehabilitation of water and sanitation services.

\section{WSS services after privatization}

In the 1990s, in line with the Egyptian government's privatization program, utilities were established in all governorates for the O\&M of water and sanitation services. Although subsidized by government funds, these utilities were allowed to retain fees obtained from meter connections and monthly bills, and to develop their own O\&M plans.

Presidential Decree No. 135 of the Year $2004^{4}$ established a national Holding Company for Water and Wastewater (HCWW). Gradually, all water and wastewater utilities in the governorates were converted to subsidiaries of the HCWW. At the same time, projects funded by external donors for the expansion of water and sanitation services have largely dwindled, and the few that continue to operate focus on institutional development rather than construction of new systems. The Egyptian government has thus become the primary and perhaps sole service provider of water and sanitation facilities. Through its branches in the governorates, the HCWW parastatal company is the primary entity officially responsible for installation of house connections and O\&M of all water supply and sanitation facilities in Egypt.

With the exception of Ismailia, Port Said, Suez, and Qaliubeya, all governorates in Egypt have their own holding companies affiliated with the HCWW. ${ }^{5}$ Two of the governorates selected for this study — Sixth of October and Menufiya — are affiliated with the government-operated HCWW for O\&M of their water supply and sanitation services. Qaliubeya, the third study governorate, was selected to provide a comparative insight into WSS service delivery before the establishment of the HCWW. At that time, water supply and sanitation services were 
implemented and managed by local government institutions, an arrangement that continues in Qaliubeya today.

Theoretically, HCWW subsidiaries are free to set their own tariffs, and they are ultimately expected to achieve complete financial self-sufficiency. They are expected to begin by covering O\&M costs, then balance depreciation of their infrastructure with revenue, and ideally in the future manage to raise and repay their own development finance for capital investments. In practice, however, the parent HCWW submits tariff requests to the Cabinet of Ministers for approval. There is strong resistance within the government toward allowing domestic water tariffs to rise sufficiently to meet cost-recovery levels.

Wastewater tariffs are set as a fixed percentage of the drinking water charge (35 percent in many governorates). However, as sewerage systems expand, many companies are becoming further in debt because of their expanded wastewater services. Rising salary, electricity, and chemical costs are also affecting companies' balance sheets. These and other obstacles continue to obstruct the performance of the HCWW and its subsidiaries and their ability to become completely privatized companies. To a large extent, government financing and subsidies continue to be a lifeline for these institutions, even while they are allowed to retain their revenues from monthly bills.

\section{LITERATURE REVIEW}

A large number of studies have investigated the impact of WSS interventions on child health worldwide (Jalan and Ravallion 2003; Glado and Briceno 2005; Bose 2009; Kolahi et al. 2009). A comprehensive review conducted by Waddington et al. (2009) on the impact of water, hygiene, and sanitation interventions on diarrhea morbidity highlighted the fact that water quality is more important than water supply in reducing diarrhea. Additionally, the authors found sanitation facilities to be as effective as hygiene in reducing diarrhea morbidity. Nevertheless, as highlighted in other recent reviews by the World Bank (2008) and Pattanayak et al. (2007), the evidence base regarding the impact of WSS interventions is still weak, particularly regarding the effects of sanitation.

To the best of our knowledge, research investigating the effect of water and sanitation quality on child health and mortality in Egypt is limited. Ashour and Ahmed (1994) conducted a study in randomly selected urban and rural areas of Dakahlia governorate in Lower Egypt and Sohag governorate in Upper Egypt. A total of 1,020 mothers were interviewed in the study areas. Using logistic regression, the probability of diarrhea was found to be high among children whose family disposed of refuse near the house or in surface water. The probability of diarrhea decreased with household ownership of land, mother's knowledge of symptoms and causes of diarrhea, and mother's previous use of oral rehydration for treatment.

More recently, Abou-Ali (2003) used data from the 1995 EDHS to examine the impact of water and sanitation on infant and child mortality in Egypt. The study applied several methods, including parametric and nonparametric duration models. Results indicated that access to 
municipal water and having a modern toilet facility decreased the risk of child mortality; sanitation was found to have a more pronounced impact on mortality than water.

Fuentes et al. (2006) addressed WSS services and child mortality in Egypt in a multicountry project that used a set of Demographic and Health Surveys (DHS) conducted in Cameroon, Egypt, Peru, Uganda, and Vietnam. The authors explored the linkages between mortality in the first year of life and different types of water sources and sanitation facilities. They used logit regressions, proportional hazard models, and propensity score matching techniques to test the consistency of their results. The paper highlighted some seemingly consistent findings across the study countries; access to safe water was generally found to be more important for infant survival in rural areas, whereas access to improved sanitation facilities increases the chances of survival in urban areas. In Egypt, however, sanitation was not found to be significant under any specification, although there was some evidence of the effects of having access to a modern toilet facility in reducing the risk of death.

\section{Methodology}

This paper relies on three data sources: a review of existing documentation on the history of water supply and sanitation in Egypt, in-depth interviews and focus group discussions with residents of three Egyptian governorates, and quantitative analysis of the Egypt Demographic and Health Surveys.

\section{Qualitative methods}

Qualitative fieldwork was conducted in eight randomly selected rural areas of three governorates (Menufiya, Qaliubeya, and Sixth of October) in Egypt's Delta area. These study locations were chosen because, as highlighted in the literature, rural areas often suffer from inferior access to improved water and sanitation facilities. The presumption was that the impact

on child health of poor WSS access would be more pronounced in these areas. ${ }^{6}$ Although rural Upper Egypt has been known to be relatively more deprived of water and sanitation services than the Delta region, the scope, budget, and short duration of the study did not allow for coverage of areas in Upper Egypt, which is farther from Cairo than the Delta. As noted above, Qaliubeya was also selected because it is one of the few governorates in Egypt in which water and sanitation services are managed by local government rather than the national government agency.

Table 1 provides a detailed outline of the study areas and groups. Within the study areas, focus group discussions were conducted with local residents, and in-depth interviews were conducted with mothers and adolescent daughters in the selected households and representatives from local schools, health clinics, and local government. Interview and focus group discussion questions are presented in Appendix 2. Districts and villages in which the study was carried out, as well as schools, health clinics, and households within those districts, were randomly selected.

As shown in Table 1, the study covered a total of nine households, five schools, and three health clinics. In general, the households included in the study can be classified as middle- to low-income families where the household heads were salaried employees or had small 
businesses, and the wives were housewives. All of the children in these families were currently enrolled in school or post-secondary education. Most of the households owned small plots of land (between 0.5 and 3 acres), which they either farmed themselves in their spare time or rented to others. ${ }^{7}$

Efforts were made to interview local WSS service providers- HCWW and its subsidiary branches in Menufiya and Sixth of October. (Qaliubeya does not have a subsidiary company.) Contact was established with the HCWW, and published information on current achievements was provided for the study. Because of the strict security measures adhered to by the HCWW, however, it was not possible to obtain interviews with officials at the headquarters level. Obtaining cooperation from the officials responsible for the Sixth of October study area also proved difficult, but successful communication was established with those responsible for the study areas in Menufiya. ${ }^{8}$

\section{Quantitative data and methods}

The quantitative analysis relies on data from the 2008 Egypt Demographic and Health Survey (2008 EDHS). This survey is the latest in a series of six full nationally representative Demographic and Health Surveys conducted in Egypt since 1988. ${ }^{9}$ The surveys provide detailed information on the background characteristics of all household members, housing conditions, ownership of durables, access to basic services, and neighborhood infrastructure. The surveys are primarily designed to provide estimates for key population indicators including fertility, contraceptive use, infant and child mortality, immunization levels, coverage of antenatal and delivery care, maternal and child health, and nutrition.

The 2008 EDHS sample was designed to provide estimates of these key population and health indicators for the country as a whole and for six major administrative regions (Urban governorates, urban Lower Egypt, rural Lower Egypt, urban Upper Egypt, rural Upper Egypt, and Frontier governorates). Additionally, the sample design allowed for governorate-level estimates of most of the key variables (except fertility and mortality rates) in the Urban governorates, Lower Egypt, and the Upper Egypt governorates. ${ }^{10}$ The 2008 EDHS successfully interviewed 18,968 households and 16,527 ever-married women aged 15-49. In these households, 10,581 children younger than age 5 were identified. These children are the primary analytical unit in this study.

Our quantitative analysis uses this national-level survey data to investigate the detailed insights obtained from the qualitative component on a large sample. A fundamental problem that arises when attempting to quantify the effect of an intervention such as a WSS service is the absence of the counterfactual outcome. In other words, if we observe a household with improved drinking water, we will not be able to simultaneously observe the same household without access to such improved services. This missing data problem generally biases the results of simple choice regressions and hazard models, since unobserved characteristics (such as tastes, values, and norms) of mothers and households may be important determinants both of the household water source and the incidence of childhood diarrhea (Fuentes et al. 2006). 
The standard solution in this context is to use panel data to control for time-invariant unobserved heterogeneity among households. In cross-sectional studies, instrumental variable (IV) techniques are sometimes used as a remedy for this potential endogeneity problem.

However, the IV technique requires a set of instrumental variables that are correlated with access to improved WSS but uncorrelated with the incidence of childhood diarrhea. Such variables are often difficult to find.

The method of matching has also been used widely in the impact evaluation literature to correct for this self-selection or simultaneity problem. Matching techniques match subjects belonging to the intervention, or treatment, group with those belonging to the untreated group based on a vector of pretreatment characteristics and/or the probability of being in treatment status. Matching techniques, however, do not control for selection based on unobserved characteristics. To reduce the possibility of selection bias when using matching methods, researchers often control for a wide range of locality and household characteristics that might be correlated with the treatment and the outcome variables.

In Egypt, no panel data are available that include rich information on both WSS and child health. The only surveys that provide this information are the cross-sectional EDHSs. Moreover, within available data sources, we did not find good instruments for household access to improved WSS that are not also correlated with child health. Accordingly, in this paper we follow most of the previous literature on WSS and use matching methods. ${ }^{11} \mathrm{We}$ depend on propensity score matching (PSM) techniques, which match treated and control groups based on the probability of being in treatment status. Throughout this paper, we define treatment status as having access to improved water supply or sanitation facilities in the household of residence.

To check the robustness of our results, for each analysis we run five different PSM matching methods as well as the naïve (unmatched) estimation. The simplest - one-to-one (or nearest neighbor) - matching method pairs each treated case with the control case that has the closest propensity score. Radius matching matches all control cases within a set caliper (in this paper, .03) to the treatment case, lessening the likelihood of bad matches. Kernel and Local Linear Regression (LLR) methods use a weighted average of all the control cases to construct the match for the treated case, placing more weight on cases whose propensity score is closer to that of the treated case. These methods tend to reduce variance but may potentially use bad matches to construct the match. The final method, five nearest neighbors, is similar to the one-to-one matching but takes the five nearest control cases to create the match for the treated case. This method again trades reduced variance for poorer matches on average (Caliendo and Kopeining 2005).

All methods are run with replacement in order to improve balance. Under all methods, cases that were off common support were eliminated from the calculation of the treatment effect. In this paper, we estimate the average treatment on the treated (ATT), which compares the mean outcome for the treated group to that of the untreated group (Jalan and Ravallion 2003). Balance for all matching analyses was achieved using a core set of variables that consists of wealth quintile (ordinal variable), region of residence, mother's education in years, father's education in 
years, and dummies for dwelling type being an apartment, house, or other. The original household wealth variable included in the EDHS dataset was not appropriate for this analysis, because the index includes a variety of measures of access to water and sanitation facilities and will bias estimates of the propensity score. Thus, a new household wealth index was calculated using principal component analysis that included all of the original EDHS wealth index variables except those related to household access to water supply and sanitation facilities.

Additional variables were needed to achieve balance in most of the matching analyses; most of these variables were dummies for different combinations of region and wealth, as urban residence and higher wealth were the most significant variables on which selection into treatment status was based.

\section{WATER AND SANitATION SERVICE DELIVERY IN EGYPT}

The two key factors to consider in regard to the impact of WSS interventions on child health are access to improved services and the quality of those services. In this section, we draw on a combination of qualitative and descriptive quantitative data to examine access to and quality of WSS services in Egypt. We begin with an overview of improvements in WSS service delivery during a 13-year period (1995-2008) drawn from EDHS surveys, then turn to a discussion of the current state of improved WSS services in terms of access and quality.

\section{Improvements in WSS service delivery 1995-2008}

Data from the EDHS demonstrate the expansion of water and sanitation services in Egypt since the mid-1990s, as shown in Figure 1. Based on the WHO/UNICEF Joint Monitoring Programme for Water Supply and Sanitation (2004), the 2008 EDHS report defines improved sources of drinking water as those including water obtained from a piped source within the dwelling, a public tap, a tubewell or borehole, or a protected well or spring. In terms of sanitation, the WHO/UNICEF Joint Monitoring Programme defines a household as having an improved toilet facility if the household has sole use of a toilet that separates waste from human contact. Based on this definition, the 2008 EDHS classifies the household as having an improved sanitation facility if it has an unshared modern or traditional flush toilet that flushes into a public sewer, vault, or septic system. These definitions for improved water and sanitation will henceforth be referred to as the WHO definitions.

Figure 1 shows that the WHO definition of water, which can be calculated consistently from the year 2000 onward, shows very little change in percentage of households with improved services. When looking only at piped connections, however, a strong upward trend is visible. The percent of households with piped connections increased by just over ten percentage points during the 13-year period, suggesting that households were moving from protected well or spring water sources to piped sources, both of which are considered improved by WHO.

Although piped water connections were common in Egypt throughout this period, the percentage of households with improved water services that did not experience a cut in water 
availability during the two weeks prior to the survey is considerably lower. As of 2005, 66 percent of households had uninterrupted, piped water, a figure which rose to 70 percent in 2008.

Turning to sanitation, Figure 1 indicates that the coverage of flush toilet facilities in Egypt increased from 84 percent of households in 1995 to near universal coverage ( 99 percent of households) in 2008. Since 2005, when the EDHS started collecting the relevant data, the vast majority of these facilities have been unshared. The percentage of households where the toilet facility was connected to the public sewer system was, however, much lower in both years. Only 57 percent of households had a toilet that was connected to the public sewer system in 2005, and 61 percent in 2008. This could have important implications for the efficacy of improved toilet facilities as a public health intervention because evacuation and disposal systems for septic tanks are not always adequate.

\section{Current state of access to improved drinking water}

By 2008, access to improved sources of drinking water was widespread in Egypt. Based on the 2008 EDHS data, Table 2 shows that more than 92 percent of Egyptian households had access to a piped water connection in the dwelling itself or to the plot. Almost all households in the Urban governorates (99.6 percent) had access to piped drinking water, followed by urban Upper Egypt (98.2 percent) and urban Lower Egypt (97.4 percent). Households in the Frontier governorates (81.2 percent) and rural Upper Egypt (82.2 percent) were the least likely to have access to a piped water connection. Nevertheless, interruption of water supply was commonly reported by households in all regions (29 percent). This was particularly true in the Frontier governorates (54 percent) and rural Upper Egypt (37 percent). Treating water, on the other hand, was uncommon, with only about 5 percent of households treating their water through any method.

Improved access to piped connections was also found to be widespread among the qualitative study households; all households had piped connections, most of which had been installed during the past ten years. ${ }^{12}$ In Menufiya and Sixth of October, water was obtained from surface sources, whereas in Qaliubeya, households were served by an artesian well ${ }^{13}$ pumping into the network. Prior to the installation of improved services, residents in the study areas had to rely on shallow hand pumps used by one or more households, standpipes, irrigation canals, or water bought from tanker trucks to supply their water needs. Although respondents perceived water quantity to be sufficient at that time, quality was low, and collecting water constituted a significant burden on women and adolescent girls, who were charged with the responsibility of fetching water and were obliged to travel several times during the day to the water source.

Interestingly, despite the availability of piped water, women respondents in a village in Qaliubeya and a village in Menufiya stated that they still visited the canal three times daily to wash cooking pots and utensils after meals. When asked the reason for this, they stated that they did not want to use too much water near the house, especially for washing, to make sure the septic tanks did not overflow and create puddles around the house. Women thought it was easier to wash pots and clothes in the canal, where water is abundant and flowing, and they believed 
that contamination would result from drinking canal water but not from washing clothing and utensils in the canal. Visiting the canal was also the only way for women to socialize and it offered a distraction from daily routines. This finding highlights the importance of considering water usage as well as access in the relationship between water supply and child health.

\section{Current state of access to improved sanitation facilities}

Although sanitation improvements have lagged behind water improvements somewhat, based on 2008 EDHS data, most households (92.9 percent) had access to improved sanitation facilities according to the WHO definition (Table 3). Just under 49 percent of households had modern flush toilets and just under 51 percent had traditional (tank or bucket) flush toilets. Only 3 percent of households shared their toilet facility with at least one other household. Although flush toilets were nearly universal, how households disposed of waste was more varied. While 62.5 percent of households had their toilet connected to a public sewer, 17.3 percent were connected to a bayara (vault), and 16.8 percent to a septic system.

Prior to the installation of improved sanitation services - and in areas like the qualitative study villages in Menufiya, where improved services have not yet been installed ${ }^{14}$ — wastewater $^{2}$ in households, schools, and other buildings was discharged into underground septic tanks that were evacuated an average of every 7 to 20 days. Residents complained that it was not possible to evacuate septic tanks often enough, as evacuation was expensive and disposal sites were inadequate. As explained by one resident:

"Before we got connected [to the improved service], we used to evacuate our septic tank every 20 days and I used to pay 8 LE (US\$1.00 = 5.6 LE in May 2010) each time. Sometimes the local unit would send us its tractor-trailer, but to get it I would have to call the local unit or visit it many times, and each time they would say, 'The tractor is not free. There's a big demand for it. You'll have to wait.' And I would wait and watch the tank overflowing and creating puddles around my house. My wife would keep yelling at the children not to play close to it, but children do not listen. And even if they empty our tank, where do they dump it? In the irrigation drain close to our house, where it brings us a lot of flies and insects and contaminates the crops we eat." (Household Head, Qaliubeya governorate, 10 May 2010)

All of the respondents in the areas where sanitation services have been improved stated that the situation has improved considerably. Although some said that there were frequent pipe blockages caused by irregular or inadequate maintenance, they also acknowledged that the response of the institutions responsible for maintenance (HCWW or local units) was prompt and blockages were fixed. The incomplete coverage of improved sanitation in rural areas does, however, point to the potential for contamination from leaking or overfull septic systems in neighboring houses or schools. 


\section{Quality of service delivery}

Another important caveat to the widespread availability of improved WSS services in Egypt is the quality of those services. Residents with improved, piped sanitation facilities were generally quite happy with the quality of the services. With regard to piped drinking water, in contrast, respondents complained of the poor quality of the water and cuts in service. Without exception, every respondent proclaimed the quality of the piped water in their households to be unsatisfactory, saying that the water had a yellowish-brown color, contained sand and other particles, and had an offensive odor and taste.

Although residents generally found the quantity of water to be adequate, the pressure in most study areas was weak; in some villages in Menufiya, water cutoffs were not uncommon. In some villages, water was cut off the first Thursday of each month for maintenance, cleaning of the main water tank, and flushing of pipes. This inconvenience was coupled by the fact that some study villages in Menufiya are located at the end of the piped network and as a result have very low water pressure. Water did not reach above the ground level, an inconvenience expressed strongly by the residents, because buildings have three floors.

The situation was even poorer in Qaliubeya, where the piped network drew from an artesian well. All respondents in this area were unsatisfied with this service, stating that the situation before piped connections (when they relied on hand pumps and the canal) was better. In addition to low pressure and poor water quality, respondents complained of frequent water cutoffs. As a result, they and all other households in the area always kept two to three large containers of water to use during times of cutoffs or when they needed large quantities for bathing or washing clothes. Storing water was common throughout the study areas. Although water availability in Menufiya and Sixth of October was better than in Qaliubeya, most respondents reported that they stored water in case of cutoffs. Some even stated that storing water is a habit that they have always maintained, even when water is readily available.

\section{EFFECT OF IMPROVED WSS SERVICES ON CHILDHOOD DIARRHEA}

In this section, we draw on the insights of the qualitative data to examine the impact of several types of improved water and sanitation services on the incidence of childhood diarrhea in Egypt.

\section{Extent and awareness of diarrhea as a child health problem}

In the 2008 EDHS, 8.49 percent of children younger than five years of age were reported by their mothers to have had diarrhea during the two-week period preceding the survey. ${ }^{15}$ Table 4 shows the prevalence of diarrhea by the characteristics of the child, his or her parents, and the household. The incidence of diarrhea was higher among children younger than 24 months, and particularly among those aged 6-11 months (18.69 percent). There was no strong difference in the incidence of diarrhea by the sex of the child; girls were slightly less likely to have had diarrhea (8.02 percent) than boys ( 8.94 percent). Diarrhea was more common among children in 
urban and rural Upper Egypt, at 12.56 and 10.56 percent, respectively, and in the Urban governorates ( 9.50 percent). No consistent difference in diarrhea prevalence between urban and rural regions was observed.

As expected, the incidence of diarrhea declined with household wealth quintile. With the exception of mothers who had no education, the prevalence of diarrhea also decreased with mother's education. The surprisingly low incidence of diarrhea reported among the children of uneducated mothers may be the result of a lower level of knowledge within this group about the symptoms of childhood diarrhea. This same pattern is also seen with father's education. Women who were working were somewhat more likely to have reported diarrhea among their children than women who were not working. Finally, whereas children living in houses and apartments had similar incidence of diarrhea (8.90 and 8.10 percent, respectively), children living in other types of dwellings, likely comprising very poor quality housing, had a higher incidence of diarrhea, at 10.80 percent.

Despite the fairly low reported incidence of diarrhea in the EDHS, the qualitative component of our research indicated that of all the diseases related to hygiene practices (and absence of or improper use of water and sanitation services), diarrhea was the most frequently reported by health clinics, residents, and school representatives in the study areas.

All the doctors and administrators at the three health clinics contacted for the study indicated that diarrhea was their patient's most common infliction, and said that children from birth through age six were the most affected. ${ }^{16}$ For example, the doctor at a family health clinic in Sixth of October reported that 65 percent of the patients treated at the clinic were children between one and two years of age suffering from diarrhea. Doctors at the other clinics gave similar estimates. Both doctors and household residents who were interviewed said that children under the age of six contracted diarrhea every three to four months.

The doctor at the clinic in Sixth of October acknowledged the relationship between diarrhea and the presence of improved water and sanitation services, adding that the percentages he quoted represented an improvement from the situation before piped water and wastewater networks were introduced. Whereas all the doctors and other health clinic staff interviewed acknowledged the relationship between diarrhea and the availability and use of improved WSS services, none of them perceived this to be the sole or major cause of childhood diarrhea. Other factors such as contaminated food, lack of proper breastfeeding, teething, and contamination from the ground (affecting crawling infants) were cited as major contributors to the high incidence of diarrhea in their areas. Residents and school officials cited major causes of diarrhea as well, particularly the consumption of street food among children of school age. As one resident said:

"Every so often I hear about children in my neighborhood falling sick from diarrhea. Maybe it's because of the water. But I'm certain of one thing: All the food being sold by vendors next to the school is responsible for the children falling sick. The food is not covered and I'm sure it's not clean. But all the children love to buy it, and so they get diarrhea." (Male household head, Qaliubeya governorate, 10 May 2010) 


\section{Awareness campaigns}

The limited health awareness activities conducted in the qualitative study areas did not provide specific messages about diarrhea and the means to prevent it. Schools in the study areas did provide occasional awareness messages to the students about hygiene, but these activities were sporadic and in many cases superficial. Awareness activities in one primary school typify such activities: Brief talks on hygiene are given by teachers or by representatives from the local health clinic during assembly hour. Otherwise, awareness messages are written on classroom or corridor walls and school fences. These messages include: "Keep your school clean," "Islam calls for cleanliness," and "Your health is in your hands." The only time disease-specific messages were relayed was during the outbreak of swine flu virus in 2009, when teachers were instructed by the Ministry of Health to communicate to students the importance of hand washing, proper use and care of bathrooms, proper sneezing, and so on.

Teachers blamed lack of time due to school shifts, lack of a specific budget for providing awareness messages, and lack of space for extracurricular activities, such as awareness campaigns, for the weakness of health education in schools. They also emphasized that awareness messages could not be successful unless reinforced by behavior at home. As one school administrator said:

"Several months ago, our teachers started talking to the children about the importance of washing hands after sneezing. The children took this seriously and we saw them doing this often. But after a couple of weeks, they went back to their old habits. During a parents' meeting, we spoke to the parents about hygiene. Some of them listened to us just to be polite. The majority of them are not educated and are simply trying to make ends meet. They have no time or patience to listen to speeches on hygiene." (Male headmaster, Qaliubeya governorate, 10 May 2010)

Local public health clinics did communicate messages about hygiene to mothers, who are the most frequent clinic visitors. Although occasional messages on hand washing were provided, most of the hygiene-awareness activities were focused on proper breastfeeding, keeping an eye on crawling infants, washing and drying clothes properly, and cutting nails. Given that most doctors and residents attributed diarrhea to factors other than water and sanitation facilities, messages on latrine cleanliness, proper water storage, and other related water issues were not among the clinics' priority topics. As with schools, health-clinic activities were limited by lack of resources.

\section{The impact of improved water supply on childhood diarrhea}

Table 5 shows the incidence of diarrhea among children younger than five by the household residence's water source. The percentage of children who experienced diarrhea is inconsistent when broken down by detailed water source, possibly due to the small number of observations in many of the categories. Children in households that do not treat their water were less likely to have experienced diarrhea than those in households that do treat their water, as we 
might expect given that households that treat water likely have a poorer quality water source. Treating water is uncommon with just under 5 percent of households treating their water. ${ }^{17}$

Based on the WHO definition of improved water, children under the age of five living in households with improved water were somewhat more likely to have experienced diarrhea in the past two weeks (8.52 percent) than those living in households with unimproved water (6.89). It is important to note, however, that the number of households with unimproved services based on the WHO definition is very small; of the 10,565 children under age five in the surveyed households, only 248 (2.4 percent) lived in households with unimproved services.

Since the qualitative study highlighted the fact that water quality issues are an important public health concern in Egypt — against the background of near-universal access to sources of drinking water that are commonly defined as improved - in this paper several other definitions of improved water are used that combine considerations of access and quality. To create these definitions, we rely on the three variables available in the EDHS that can serve as proxies for water quality: interruption of water supply, water storage, and water treatment. Correspondingly, a household is defined as having had an improved-uninterrupted source of drinking water if it had access to a piped source of drinking water within the dwelling plot with no water supply interruption in the past two weeks. A household is defined as having had improved-unstored drinking water if it had access to an improved source of drinking water and did not store that water before use. A household is defined as treating its water if it used any form of water treatment; as noted above, this is uncommon in Egypt.

As indicated in Figure 1, the improved-uninterrupted definition of water supply yields a much lower percent of households with improved services compared to the broader WHO definition for improved water. Under the improved-uninterrupted definition, 6,338 of the children under age five (60 percent) lived in households with an improved water source. As shown in Table 5, 7.16 percent of the children who lived in a household with improveduninterrupted water service had experienced diarrhea in the two weeks prior to the survey, compared with 10.47 percent among the combined group of children in households with either unimproved or improved-interrupted service. Looking only at those with improved-interrupted service, the incidence of diarrhea was slightly higher at 10.87 percent. The incidence of diarrhea was also higher among those whose households had improved-stored water, at 10.67 percent, compared with 7.95 percent among children in households with improved-unstored water. Diarrhea incidence was also higher among the small number of children whose households treated their drinking water. ${ }^{18}$

\section{Propensity score matching results}

Propensity score matching (PSM) analysis was carried out to assess the impact of improved water service on childhood diarrhea in a multivariate framework. In this analysis, children in the "treated" group with superior water service, by each respective definition, were matched to children in the "control" group with inferior service according to the same definition. Because of the small number of children living in households with unimproved water according 
to the WHO definition, adequate balance on the children's background characteristics could not be achieved and the results are thus unreliable. The PSM matching output (Table A4), balance statistics (Table A5), and common support graphs before and after matching (Figure A1) for this analysis can be found in Appendix 1.

For the improved-uninterrupted definition of water service, the distributions of the treated and control group propensity scores were brought much closer after matching, as shown in Figure 2. Balance statistics for this analysis can be found in Table A6 in Appendix 1; very good balance was achieved on all covariates. PSM matching results are shown in Table 6, comparing children in households with improved-uninterrupted water to children in all other households. Under all matching routines, large negative average treatment effects on the treated (ATT) were found, indicating that having an improved-uninterrupted water source did have a significant effect in reducing the incidence of childhood diarrhea as compared with other (unimproved or improved-interrupted) sources. The treatment effect was somewhat smaller under the one-to-one matching routine than with other methods.

To check the robustness of these results, this analysis is reproduced in Table 7, but matching children in households with improved-uninterrupted water (treatment) only to children in houses with improved-interrupted water (for balance statistics see Table A7 in Appendix 1). The large negative effects hold, and the magnitude of the t-statistic is even larger. This indicates that having an uninterrupted source of water has a significant negative effect on the incidence of childhood diarrhea, compared with having an interrupted source of water, even among households with improved water supply. This analysis was also carried out matching children in households with improved-uninterrupted water to children in households with unimproved water, but owing to the small number of children in the latter category, adequate balance could not be achieved.

Because the qualitative data suggested that a common response by households to frequent water cutoffs is water storage, an additional analysis was conducted matching children in households that did not store their water (treatment) to children in households where water was stored. ${ }^{19}$ Data from the 2008 EDHS did confirm that storing water is more common when the household experienced water cutoffs: 39 percent of children living in households with interrupted water also had households that stored water, compared with only 9 percent of children in households with an uninterrupted water supply.

Children living in households that stored water were thus expected to have worse health outcomes, both because of the association between water cutoffs and storage, and because improper water-storage techniques may increase risk of contamination and thereby lead to diarrhea. Indeed, the matching results shown in Table 8 indicate a negative effect on childhood diarrhea of having improved-unstored water compared with having improved-stored water (for balance statistics see Table A8 in Appendix 1). Taken together, these results indicate that water quality issues - particularly the interruption of water supply and the associated practice of storing water-are an important child health concern, despite the near-universal improved water supply in Egypt. 


\section{Analysis by mother's education}

The effect of improved water supply on child health may vary by the child's household characteristics, and particularly the education of female members of the household, as shown by Jalan and Ravallion (2003). ${ }^{20}$ In order to test this finding in Egypt, the above PSM analysis of improved-uninterrupted water supply was divided by three categories of the mother's education: 0 years of education, 1-6 years (generally equivalent to primary school), and 7 or more years. For each analysis, the sample was restricted only to children whose mothers had the specified level of education. PSM matching was then conducted between children with improveduninterrupted water supply and all other children within the subsample. The PSM matching results of this analysis is presented in Tables $9 \mathrm{a}-\mathrm{c}$. In all analyses, children with improveduninterrupted water supply are compared to all other children, which is the combined group of children with unimproved or improved-interrupted water supply. Balance statistics for these analyses are shown in Tables A9a-c in Appendix 1, respectively.

Table 9a indicates that, when comparing only between children whose mothers have no formal education, having an improved-uninterrupted source of drinking water had a highly significant negative effect on the incidence of childhood diarrhea. The same was true when comparing among children whose mothers had 1 to 6 years of education (see Table 9b), and the treatment effect was in fact somewhat larger. Among children whose mothers had 7 or more years of education, in contrast, no significant treatment effect was found under the one-to-one matching and five nearest neighbor routines, and a much smaller treatment effect, significant only at the 10 percent level, was found under the other three routines. It should be noted, however, that balance between the treated and control groups was not as good for this level of mother's education.

Taken together, these results suggest that improved water has a considerably more important effect on the incidence of childhood diarrhea among households where the mother has little education. This is the opposite of Jalan and Ravaillon's finding in rural India; however it suggests that improved facilities are particularly important in Egypt among groups with lower knowledge of hygiene practices, which, as highlighted in the qualitative study, have not necessarily changed with the introduction of improved water. It may be that among households with higher-educated mothers, hygiene practices are better, so that water source is less important. Among households with lower-educated mothers, improved water may have a significant impact on child health against the backdrop of improper hygiene practices.

\section{Analysis by rural-urban residence}

The effect of poor quality WSS services on child health may be different in crowded urban areas as compared with less populated rural areas. In addition, quality of service problems are likely to be more common in rural areas. To examine how these rural-urban differences may be affecting the results, another PSM analysis of the improved-uninterrupted water supply definition was conducted, this time dividing the sample based on urban and rural residence. 
As expected, having an interrupted water supply was more common in rural areas; 45.5 percent of rural children under age five lived in a household where the water had been cut off at least once in the past two weeks, compared with 32.4 percent of urban children. PSM matching analysis showed that, under the radius, kernel, and local linear regression matching techniques, having an improved-uninterrupted water supply had a highly significant negative effect on the incidence of diarrhea among children in rural areas (Table 10a). However, no significant effect was found among children residing in urban areas, regardless of the matching method (Table $10 \mathrm{~b})$. This suggests that the results for the combined sample are driven primarily by the effect of improved-uninterrupted services on childhood diarrhea in rural areas (rural children constitute 63 percent of the sample). Meanwhile, whether or not an urban household experiences water cutoffs appears to have little impact on child health. Balance statistics for the rural and urban analyses are shown in Tables A10a and A10b, respectively, in Appendix 1.

\section{The impact of improved sanitation facilities on childhood diarrhea}

Table 11 indicates that children living in households with modern flush toilets were the least likely to have experienced diarrhea in the two weeks prior to the 2008 EDHS survey, at 7.85 percent. ${ }^{21}$ Children living in households with traditional tank flush toilets, no toilet facility, or other facilities (the latter having very few observations) were the most likely to have experienced diarrhea. Altogether, 1,028 children under the age of five (10.87 percent of the sample) were found to be living in households with unimproved sanitation according to the WHO definition, which is defined as sole use of a toilet that separates waste from human contact. Among these children, the incidence of diarrhea was somewhat higher than among children living in households with improved facilities, at 9.26 percent and 8.40 percent, respectively.

As with water supply, the qualitative study highlighted the importance of service delivery issues, in addition to access, in defining improved sanitation facilities. In particular, inadequate evacuation and disposal services for bayara and septic tanks were found to be a significant problem in the study areas. Correspondingly, in the quantitative analysis, we define a household as having improved-connected sanitation facilities if it has sole use of a modern or traditional flush toilet connected to a public sewer. Figure 1 shows that access to an improved-connected facility is considerably low, with approximately 61 percent of households having such a facility in 2008. Fifty-four percent of children under the age of five identified by the 2008 EDHS lived in a household without improved-connected facilities. However, Table 11 shows that these children had a slightly lower incidence of diarrhea ( 8.10 percent) than children with improved facilities under the narrower definition (8.85 percent).

Due to the small number of children living in households with unimproved facilities according to the WHO definition, relative to the number living in households with improved services, adequate balance could not be obtained for the PSM matching analysis for this definition. The PSM matching results (Table A11), balance statistics (Table A12), and common support graphs before and after matching (Figure A2) can be found in Appendix 1. 
For the improved-connected definition for sanitation, good balance was achieved between the improved-connected (treated) and improved-unconnected plus unimproved (control) groups after matching, as shown in the common support graphs in Figure 3 and the balance statistics (Table A13 in Appendix 1). Counter to expectations, all of the treatment effects for this analysis were positive, indicating that having an improved-connected sanitation facility leads to a greater incidence of diarrhea among children under age five. While the effect is not significant under the one-to-one matching routine, the radius, kernel, and LLR routines produced t-statistics in the range of 1.89-2.06, just bordering on significance at the .05 level. The five nearestneighbor routine yielded a positive treatment effect significant at the .01 level.

To explore this unexpected positive effect further, an additional analysis was carried out matching children living in households with improved-connected facilities to those living in households with improved-unconnected facilities. This analysis produced very similar results (not shown), which is not surprising given that only 454 children were living in households with unimproved facilities. ${ }^{22}$

A third analysis was then carried out based on the insight from the qualitative data that children may be exposed to contaminated groundwater from leaking or improperly emptied septic tanks in their neighborhood or school, even if their household residence had improvedconnected facilities. For this analysis, we restricted the sample to only children who lived in a household with improved-connected sanitation facilities. The treatment was then defined as living in an enumeration area in which no other households in the sample had a septic tank or bayara, while the control group was defined as living in an enumeration area in which another household had a septic tank or bayara. Having an improved-connected toilet facility was expected to have a stronger effect on childhood diarrhea in areas where no septic tanks or bayara were found, because these children would not be exposed to as much contamination from nonhousehold sources.

The analysis did not produce any significant results (see Table 13; balance statistics presented in Table A14 in Appendix 1). It is important to note that the DHS enumeration area may not be the most accurate measure of a child's living environment outside the household. Unfortunately, other measures that can proxy for the immediate neighborhood are not available in the dataset. Furthermore, since the DHS is not a census survey, there may in fact be households with septic tanks or bayara in the enumeration areas coded as treatment (tank-free) in our analysis, but because these households were not sampled in the DHS, we cannot identify their existence.

\section{Analysis by mother's education}

When broken down by mother's education, PSM matching results for the improvedconnected definition produced significant results only when comparing between children whose mothers had 0 years of education (see Table 14; balance statistics presented in Table A15 in Appendix 1). At this level of education, the one-to-one matching routine gave insignificant results, while the radius, kernel, and LLR routines yielded positive treatment effects significant 
at the .10 level. The five nearest neighbor treatment effect was significant at the .05 level. When comparing between children whose mothers had 1-6 or 7 or more years of schooling, positive but insignificant treatment effects were found with all matching routines, with the exception of the five nearest neighbor method when the mother had 7 or more years of schooling. These results, while not conclusive, seem to suggest that whatever factor is driving the unexpected positive treatment effect for sanitation is more influential among women with no education.

\section{Analysis by rural-urban residence}

When broken down by rural versus urban residence, access to improved-connected sanitation services was found to be considerably more concentrated in urban areas than was access to improved-uninterrupted water supply. Whereas only 26.4 percent of children under age five in rural areas had access to an improved-connected facility, 78.8 percent of urban children did. PSM analysis again suggests that the overall sample results are being driven by treatment effects in rural areas; whereas having an improved-connected sanitation facility was found to have a significant, positive effect on the incidence of childhood diarrhea in rural areas (under four of the matching techniques), no significant treatment effects were found in urban areas. It is important to note, however, that balance for the urban areas analysis, while improved over the unmatched sample, was not optimal (see tables A16a and A16b in Appendix 1). ${ }^{23}$

The qualitative study's highlighting of a range of service-provision issues regarding water supply and sanitation suggests that another factor related to the quality of sanitation facilities may be driving this positive result. Unfortunately, no other variables are available in the EDHS that can serve as proxies for sanitation quality. There is no measure, for example, of whether flooding or backups of the sewer system were a common occurrence in the child's area of residence. The EDHS enumeration area may not be the best proxy for whether children were exposed to contaminated water from septic tanks that were in their area of residence but not attached to their own household. The type of sanitation facility in the child's school, or in the households of relatives outside the enumeration area, may be a more appropriate proxy, but this information cannot be derived from the EDHS. These results thus highlight the need for more detailed data on the quality of service provision in local areas to better understand the health impact of WSS interventions.

\section{CONCLUSION AND RECOMMENDATIONS}

This paper examines the impact of improved water supply and sanitation services on childhood diarrhea in Egypt using a combination of qualitative and quantitative data. The qualitative and quantitative findings agree that widespread access to improved sources of drinking water and toilet facilities exists across Egypt, with the exception of more remote rural areas, based on commonly used WHO definitions. Access to piped water and flush toilet facilities has increased considerably during the past 15 years, progress that was noted with satisfaction by many of the rural residents interviewed. 
The qualitative data also indicated, however, that the quality and regularity of WSS services is a significant problem in Egypt, despite widespread access to improved services. Residents complained of poor water quality, low pressure, and frequent stoppages; as a result many stored water in preparation for service cutoffs. In terms of sanitation, it was found that even when households were equipped with a flush toilet, septic tanks and bayara—which as indicated by the quantitative data, are quite common in Egypt - were emptied infrequently, leading to leakages. Some local disposal services were also said to dump the waste into local waterways.

Drawing on these insights from the qualitative data, propensity score matching analysis was carried out to examine the impact of an improved-uninterrupted water source and an improved-connected sanitation facility on childhood diarrhea. Access to an improveduninterrupted water source was found to have a significant negative effect on the incidence of childhood diarrhea, whether measured against all other cases or only against children in households with improved but interrupted water supply. Not storing water, a practice that is likely related to the consistent availability of water, was also found to have a significant negative effect on the incidence of childhood diarrhea. The negative effect of improved-uninterrupted water supply on childhood diarrhea was found to be strongest among children whose mothers had little or no education. The overall result also appears to be driven by the strong negative treatment effect in rural areas, whereas no significant effect was found in urban areas. These results indicate that interrupted water supply is an important child health issue in Egypt, particularly in rural areas and among families with mothers who had little education, and needs to be addressed.

Contrary to expectations, having an improved-connected sanitation facility in the household was associated with a positive treatment effect. In other words, children with improved sanitation facilities that were connected to the public sewer system were more likely to experience diarrhea. Available EDHS data were not sufficient to determine whether this surprising result is related to the definition of the control group or the presence of septic tanks or vaults in the neighborhood that may be causing contamination. However, as with improveduninterrupted water supply, these results appear to be driven by large treatment effects in rural areas, as the analysis in urban areas again proved insignificant.

These somewhat contradictory findings lead to several recommendations for policy makers and researchers concerned with water supply and sanitation. This analysis suggests that both quality of service issues and health behaviors intervene in the relationship between improved services and health outcomes. Intervening factors may include the reliability of improved services at the local level, the distribution of those services, the nonuse of improved water for different types of household needs, water storage practices, the frequency of septic tank evacuation, hygiene behaviors, and awareness of accurate health information. Investing in basic WSS infrastructure, a goal toward which Egypt has made significant progress, is therefore not enough to achieve improved child health. 
In terms of health behaviors, the qualitative component of this study finds that the provision of improved WSS services is not necessarily associated with improved hygiene practices. Residents were found to have more or less maintained the same frequency of washing practices and still washed dishes in canals. These findings may be attributed to two major factors. First, the inadequacy of the present services, especially in regard to water-provision regularity, may discourage residents from frequent washing. Second, respondents (especially mothers) lack awareness of the seriousness of childhood diarrhea and the important role that hygiene plays in child health. The incidence of diarrhea among children was not commonly associated with water and sanitation services; rural residents interviewed in the qualitative study were more likely to blame street food. Diarrhea was also not one of the diseases residents were most concerned about in relation to WSS services.

More alarming was the fact that health professionals in the qualitative study areas also seemed to discount the importance of water and sanitation services as a cause of childhood diarrhea. This suggests that a critical gap in the provision of health messages exists in Egypt regarding the causes of this widespread childhood disease and its potentially serious consequences. Further research is called for to assess the extent to which health professionals throughout Egypt have accurate information about the causes of diarrhea and other common childhood diseases, as well as the role of WSS services in preventing such diseases.

The limited scale of awareness campaigns regarding childhood diarrhea in the study areas indicates that more resources need to be devoted to disseminating health messages. Health messages regarding diarrhea need to stress the seriousness of the disease and disseminate accurate information about causes. To be more effective, these messages need to be targeted toward multiple groups, including families, teachers, and health professionals. Mothers are a particularly important group to target, as they are often the ones reinforcing hygiene practices at home. The fact that improved-uninterrupted water services have a greater effect on the health of children of mothers with limited education may also have something to do with health behaviors among this demographic group.

Quality of service issues are another important factor mediating the effect of improved WSS services on child health. At least one such quality issue — cuts in water supply—was shown to have a significant effect on child health. Given the range of service-quality issues highlighted in the qualitative component of the study, it seems likely that there are other, unobserved, characteristics of WSS services in local areas that also are affecting child health. These unobserved characteristics, perhaps stemming from the nonrandom placement of water and sanitation services, may explain the unexpected positive treatment effect found for improvedconnected sanitation services.

On a policy level, these results indicate that interventions are needed to improve the quality of service delivery for both water and sanitation, particularly in rural areas. In addition to affecting health, inadequate water-service delivery appears to reinforce improper health practices, such as washing dishes in canals and storing water in ways that are not sanitary. Qualitative evidence that sanitation disposal services are inadequate for the large population of 
children whose households are not connected to the public sewer system is also a cause for concern.

The study results, and particularly the positive treatment effect found for improvedconnected sanitation, also indicate that current data regarding WSS service delivery is inadequate. In addition to collecting data on whether a household has access to improved services, surveys should collect more detailed information on the quality of those services. More detailed data on hygiene practices, such as hand washing, could help to separate the effects of hygiene and service delivery on child health. Furthermore, household level alone does not appear to be sufficient to capture children's potential exposure to contaminated water or sewage. The type of sanitation services available at schools or relatives' houses, as well as the occurrence of pipe breakages or septic tank leaks and overflows in the neighborhood, are all important indicators of a child's health environment. A new generation of survey data collection and analysis is called for to gain a better understanding of the effects of WSS on child health in developing countries. 


\section{NOTES}

1 Information for this section was taken from USAID (2006).

2 MHUUD offices were located at the governorate level, and district representatives were present at the local units level, which are village conglomerates.

3 SFD is a multidonor organization established in 1991 as a social safety net associated with the government's agreement to undertake an extensive Economic Reform and Structural Adjustment Program.

4 See $\langle$ http://www.hcww.com.eg/en/Content.aspx?ID=4> for the full text of this decree.

5 Water and sanitation services in Ismailia, Port Said, and Suez are provided and managed by the Suez Canal Authority, an independent governmental entity that also provides and manages most of the other services in these governorates. According to HCWW sources, the Suez Canal Authority is expected to turn over O\&M of water supply and sanitation in the near future.

6 Improved water and sanitation services may also be inadequate in urban areas, notably the outlying fringes and informal impoverished areas of cities such as Cairo and Alexandria. The legal insecurity of these informal settlements, however, gives rise to a general distrust of outsiders by residents, making qualitative research difficult.

7 See Table A1 in Appendix 1 for age and educational profile of study population.

8 Apart from the published data, information on the HCWW provided in this study is based on the third author's prior experience with the company and similar prior studies conducted by the author in other governorates, where contacts were successfully made with HCWW officials at its headquarters and subsidiary companies.

9 In addition, three interim DHS surveys were conducted in 1997, 1998, and 2003. See Measure DHS <http://www.measuredhs.com/Where-We-Work/CountryMain.cfm?ctry_id=10\&c=Egypt\&Country=Egypt $\& \mathrm{cn}=)>$ for more information on those surveys.

10 See El-Zanaty and Way (2009) for a more detailed description of the 2008 EDHS sample design.

11 For a discussion of the matching techniques, see Jalan and Ravallion (2003) and Ravallion (2005).

12 See Table A2 in Appendix 1 for details on water service delivery status of study households, as well as the households' ratings of the quantity and quality of their water.

13 An artesian well is an underground well dug to a depth that conforms to engineering standards (as opposed to a hand pump that is usually dug at shallow depths by local artisans) and connected to a pipe network (main, secondary, and tertiary pipes) and in some areas a storage tank. The well serves as a treatment compound that provides the same services as a surface water treatment plant, but with a different source of water.

14 See Table A3 in Appendix 1 for details on the sanitation service delivery status of the study households. 
15 As highlighted by El-Zanaty and Way (2009), this number should be considered with caution. The reported figures are subject to recall bias by the mothers and their subjective assessment of the child's illness. Also, there are seasonal variations in the pattern of diarrheal illnesses. Hence, the reported percentages of diarrhea episodes represent the prevalence of diarrhea during the time of the 2008 EDHS interviews, which took place March to May 2008, and not necessarily the situation during other times of year.

16 Apart from the DHS, accurate statistics could not be obtained on the health status of children in Egypt in general, and in the study areas in particular. Although doctors and administrative officials in the village health clinics were contacted, these institutions do not keep records tracking the incidence and frequency of diseases or other relevant information. Figures provided by the health clinic doctors and administrators are therefore estimates provided by the contacted individuals and should be considered with caution. Since these individuals are also residents of the study areas, however, their estimates can be taken to represent general trends witnessed in their areas.

17 Among households that treated their water, the most common treatment methods were filtering (57 percent) and letting water stand and settle (31 percent).

18 By the WHO definition of improved water, 4.35 percent of children living in households with improved water sources also had their water treated, compared with 0.1 percent of children living in households with unimproved water. Using the improved-uninterrupted definition, these figures were 3.12 percent among those with improved water and 5.93 percent among those with unimproved water. Water treatment does not appear to be strongly associated with having an unimproved water source.

19 This analysis was also carried out matching children in households with improved-unstored water to children in households with unimproved water, but owing to the small number of children in the latter category, adequate balance could not be achieved. In addition, an analysis was conducted matching children in households with improved-untreated water to children in households with improved-treated water and unimproved water, respectively. Because of the small number of children in both of the two control groups, however, balance could not be achieved in either analysis, and results are not presented here.

20 Jalan and Ravallion find that in rural India the benefits of piped water are less for children from families in which the female members have little education.

21 Too few observations were made in the bucket-toilet category for the zero result to be considered reliable.

22 Adequate balance could not be achieved to match these 454 children to those with improved-connected facilities.

23 The analysis comparing children in areas with a septic tank or bayara and those in areas without, among children with improved-connected services, was also carried out on the rural-only sample. This analysis showed a significant, positive treatment effect of living in an area without a septic tank or bayara on childhood diarrhea. 


\section{REFERENCES}

Ashour, S.K., M.E. Ahmed 1994. Logistic regression for social-economic and cultural factors affecting diarrhea diseases in children under two years in Egypt. Egypt Population and Family Planning Review 28(1): 1-18.

Abou-Ali, Hala. 2003. The effect of water and sanitation on child mortality in Egypt. Working Papers in Economics, No. 112. Göteborg University, Department of Economics.

Bose, Ron. 2009. "The impact of water supply and sanitation interventions on child health: Evidence from DHS surveys.” Mimeo. New Delhi, India: International Initiative for Impact Evaluation. (Unpublished.)

Caliendo, Marco and Sabine Kopeining. 2005. Some Practical Guidance for the Implementation of Propensity Score Matching. Bonn, Germany: IZA Discussion Paper No. 1588.

El-Zanaty, Fatma and Ann Way. 2009. Egypt Demographic and Health Survey 2008. Cairo, Egypt: Ministry of Health, El-Zanaty and Associates, and Macro International.

Fuentes, Ricardo, Tobias Pfutze, and Papa Seck. 2006. Does Access to Water and Sanitation Affect child survival? A five country analysis. Human Development Report Office Occasional Paper. United Nations Development Programme.

Glado, Virgilio and Bertha Briceno. 2005. Evaluating the Impact on Child Mortality of a Water Supply and Sewerage Expansion in Quito: Is Water Enough? Office of Evaluation and Oversight Working Paper No. 0105. Washington, DC: Inter-American Development Bank.

Jalan, Jyotsna and Martin Ravallion. 2003. "Does piped water reduce diarrhea for children in rural India?” Journal of Econometrics 112(1): 153-173.

Kolahi A.A., A. Rastegarpour, M.R. Sohrabi, 2009. "The impact of an urban sewerage system on childhood diarrhoea in Tehran, Iran: A concurrent control field trial." Transactions of the Royal Society of Tropical Medicine and Hygiene 103(5): 500-505.

Pattanayak, Subhrendu K., Katherine L. Dickinson, Jui Chen Yang, Purujit Praharaj, and Christine Poulous. 2007. "Promoting latrine use: Midline findings from a randomized evaluation of a 54-community mobilization campaign in Bhadrak, Orissa.” Working Paper No. 0702. North Carolina: Research Triangle Institute.

Ravallion, Martin. 2005. Evaluating Anti-Poverty Programs. Policy Research Working Paper No. 3625. Washington, DC: World Bank.

Waddington, Hugh, Birte Snilstveit, Howard White, and Lorna Fewtrell. 2009. Water, Sanitation and Hygiene Interventions to Combat Childhood Diarrhoea in Developing Countries. 
Synthetic Review No. 001. New Delhi, India: International Initiative for Impact Evaluation (3ie).

USAID. 2006. Evaluation of USAID/Egypt's Utility Projects. Egypt: USAID.

WHO/UNICEF Joint Monitoring Programme for Water Supply and Sanitation. 2004. Meeting the MDG Drinking Water and Sanitation Target: A Mid-Term Assessment of Progress. Geneva: WHO.

World Bank. 2008. The Health Benefits of Water Supply and Sanitation Projects: A Review of the World Bank Lending Portfolio. Washington, DC: World Bank. 
Table 1 Study areas and groups

\begin{tabular}{|c|c|c|c|}
\hline Governorate & District & Village & Type of study group \\
\hline \multirow[t]{9}{*}{ Menufiya } & \multirow[t]{6}{*}{ District 1} & $\begin{array}{l}\text { Village } 1 \\
\text { (satellite village) }\end{array}$ & Primary and preparatory (mixed) school \\
\hline & & $\begin{array}{l}\text { Village } 2 \text { (satellite } \\
\text { village) }\end{array}$ & Water treatment plant operator \\
\hline & & \multirow[t]{4}{*}{$\begin{array}{l}\text { Village } 3 \text { (satellite } \\
\text { village) }\end{array}$} & Household (9 members) \\
\hline & & & Household (8 members) \\
\hline & & & Household (6 members) \\
\hline & & & Household (5 members) \\
\hline & \multirow[t]{2}{*}{ District 2} & Village 4 & Health clinic \\
\hline & & $\begin{array}{l}\text { Village } 5 \text { (main } \\
\text { village) }\end{array}$ & Primary (mixed) school \\
\hline & District 3 & $\begin{array}{l}\text { Village } 6 \text { (main } \\
\text { village) }\end{array}$ & Primary girls' school \\
\hline \multirow[t]{6}{*}{ Qaliubeya } & \multirow[t]{6}{*}{ District 1} & \multirow{6}{*}{$\begin{array}{l}\text { Village } 1 \\
\text { (main village) }\end{array}$} & Primary (mixed) school \\
\hline & & & Family health clinic \\
\hline & & & Local unit \\
\hline & & & Household (6 members) \\
\hline & & & Household (5 members) \\
\hline & & & Household (5 members) \\
\hline \multirow{4}{*}{$\begin{array}{l}\text { Sixth of } \\
\text { October }\end{array}$} & \multirow[t]{4}{*}{ District 1} & \multirow[t]{4}{*}{ Village 1} & Primary (mixed) school \\
\hline & & & Family health clinic \\
\hline & & & Household (7 members) \\
\hline & & & Household (3 members) \\
\hline
\end{tabular}


Table 2 Household drinking water access and treatment by residence

\begin{tabular}{|c|c|c|c|c|c|c|c|c|c|c|c|}
\hline \multirow[b]{2}{*}{ Drinking water } & \multirow[b]{2}{*}{ Urban } & \multirow[b]{2}{*}{ Rural } & \multirow{2}{*}{$\begin{array}{l}\text { Urban } \\
\text { gover- } \\
\text { norates }\end{array}$} & \multicolumn{3}{|c|}{ Lower Egypt } & \multicolumn{3}{|c|}{ Upper Egypt } & \multirow{2}{*}{$\begin{array}{l}\text { Frontier } \\
\text { gover- } \\
\text { norates }\end{array}$} & \multirow{2}{*}{$\begin{array}{r}\text { Total } \\
\text { households }\end{array}$} \\
\hline & & & & Total & Urban & Rural & Total & Urban & Rural & & \\
\hline \multicolumn{12}{|c|}{ Source of drinking water ${ }^{a}$} \\
\hline $\begin{array}{l}\text { Improved source } \\
\text { Piped into }\end{array}$ & 99.8 & 96.7 & 99.9 & 98.6 & 99.8 & 98.1 & 96.9 & 100.0 & 95.1 & 88.4 & 98.2 \\
\hline residence/plot & 98.5 & 86.7 & 99.6 & 92.2 & 97.4 & 90.0 & 88.2 & 98.2 & 82.2 & 81.2 & 92.4 \\
\hline Public tap & 0.6 & 4.3 & 0.3 & 2.0 & 0.4 & 2.7 & 4.7 & 1.4 & 6.7 & 1.4 & 2.5 \\
\hline Tubewell/borehole & 0.2 & 3.3 & 0.0 & 2.8 & 0.7 & 3.8 & 1.7 & 0.1 & 2.6 & 0.1 & 1.8 \\
\hline Protected well/spring & 0.5 & 2.4 & 0.0 & 1.5 & 1.4 & 1.5 & 2.3 & 0.2 & 3.6 & 5.6 & 1.5 \\
\hline Unimproved source & 0.2 & 3.2 & 0.1 & 1.3 & 0.1 & 1.8 & 3.0 & 0.0 & 4.8 & 11.5 & 1.7 \\
\hline $\begin{array}{l}\text { Unprotected } \\
\text { well/spring }\end{array}$ & 0.0 & 0.0 & 0.0 & 0.0 & 0.0 & 0.0 & 0.0 & 0.0 & 0.1 & 0.2 & 0.0 \\
\hline Tanker truck/cart & 0.2 & 3.1 & 0.1 & 1.3 & 0.1 & 1.8 & 3.0 & 0.0 & 4.7 & 11.3 & 1.7 \\
\hline Surface water & 0.0 & 0.0 & 0.0 & 0.0 & 0.0 & 0.0 & 0.0 & 0.0 & 0.1 & 0.0 & 0.0 \\
\hline Other/missing & 0.0 & 0.1 & 0.0 & 0.1 & 0.1 & 0.1 & 0.0 & 0.0 & 0.1 & 0.1 & 0.0 \\
\hline \multicolumn{12}{|c|}{ Water supply interrupted } \\
\hline Not interrupted & 74.3 & 67.8 & 77.9 & 71.9 & 74.1 & 70.9 & 65.9 & 70.5 & 63.2 & 45.9 & 70.9 \\
\hline Daily/almost daily & 7.9 & 9.1 & 8.1 & 8.5 & 7.8 & 8.8 & 7.9 & 5.5 & 9.3 & 34.3 & 8.5 \\
\hline Few times per week & 10.9 & 15.0 & 9.9 & 12.7 & 11.3 & 13.2 & 15.4 & 11.8 & 17.6 & 15.9 & 13 \\
\hline Less frequently & 6.5 & 7.7 & 3.7 & 6.6 & 6.4 & 6.6 & 10.3 & 11.9 & 9.4 & 3.4 & 7.1 \\
\hline Don't know/missing & 0.4 & 0.4 & 0.4 & 0.4 & 0.4 & 0.4 & 0.4 & 0.3 & 0.5 & 0.5 & 0.4 \\
\hline \multicolumn{12}{|c|}{ Water treated prior to drinking } \\
\hline Not treated & 93.8 & 96.3 & 95.1 & 94.8 & 92.8 & 95.6 & 95.6 & 92.9 & 97.2 & 92.2 & 95.1 \\
\hline Boiled & 0.6 & 0.3 & 0.5 & 0.4 & 0.7 & 0.3 & 0.5 & 0.6 & 0.4 & 0.4 & 0.4 \\
\hline Bleach/chlorine added & 0.0 & 0.0 & 0.0 & 0.0 & 0.0 & 0.0 & 0.0 & 0.0 & 0.0 & 0.1 & 0.0 \\
\hline $\begin{array}{l}\text { Strained through } \\
\text { cloth/cotton }\end{array}$ & 0.4 & 0.1 & 0.5 & 0.2 & 0.4 & 0.1 & 0.2 & 0.2 & 0.1 & 0.4 & 0.3 \\
\hline Water filter used & 4.6 & 1.3 & 3.5 & 2.9 & 5.9 & 1.7 & 2.3 & 5.1 & 0.7 & 4.9 & 2.9 \\
\hline Solar disinfection & 0.0 & 0.0 & 0.0 & 0.0 & 0.0 & 0.0 & 0.0 & 0.0 & 0.0 & 0.0 & 0 \\
\hline Stand and settle/other & 0.8 & 2.2 & 0.4 & 1.9 & 0.7 & 2.5 & 1.6 & 1.4 & 1.6 & 2.3 & 1.5 \\
\hline Total & 9,159 & $\mathbf{9 , 8 0 9}$ & 4,182 & 8,348 & 2,466 & 5,881 & 6,204 & 2,338 & 3,865 & 235 & 18,968 \\
\hline
\end{tabular}


Table 3 Household sanitation facilities by residence

\begin{tabular}{|c|c|c|c|c|c|c|c|c|c|c|c|}
\hline \multirow[b]{2}{*}{ Sanitation } & \multirow[b]{2}{*}{ Urban } & \multirow[b]{2}{*}{ Rural } & \multirow{2}{*}{$\begin{array}{r}\text { Urban } \\
\text { govern- } \\
\text { orates } \\
\end{array}$} & \multicolumn{3}{|c|}{ Lower Egypt } & \multicolumn{3}{|c|}{ Upper Egypt } & \multirow{2}{*}{$\begin{array}{c}\text { Frontier } \\
\text { gover- } \\
\text { norates }\end{array}$} & \multirow{2}{*}{$\begin{array}{r}\text { Total } \\
\text { house- } \\
\text { holds } \\
\end{array}$} \\
\hline & & & & Total & Urban & Rural & Total & Urban & Rural & & \\
\hline \multicolumn{12}{|l|}{ Sanitation facility } \\
\hline Modern flush toilet & 77.1 & 21.8 & 83.8 & 43.9 & 76.7 & 30.1 & 30.6 & 66.2 & 9.1 & 53.4 & 48.5 \\
\hline $\begin{array}{l}\text { Traditional tank flush } \\
\text { toilet }\end{array}$ & 1.3 & 2.7 & 1.0 & 1.5 & 0.8 & 1.8 & 3.3 & 2.2 & 4.0 & 4.7 & 2.0 \\
\hline $\begin{array}{l}\text { Traditional bucket flush } \\
\text { toilet }\end{array}$ & 21.4 & 74.1 & 15.1 & 54.2 & 22.4 & 67.6 & 64.1 & 31.2 & 84.1 & 39.7 & 48.7 \\
\hline Pit latrine/ bucket toilet & 0.1 & 0.6 & 0.1 & 0.1 & 0.1 & 0.1 & 0.9 & 0.1 & 1.3 & 1.3 & 0.4 \\
\hline Other/missing & 0.0 & 0.1 & 0.0 & 0.1 & 0.0 & 0.2 & 0.1 & 0.0 & 0.1 & 0.0 & 0.1 \\
\hline No facility & 0.1 & 0.7 & 0.0 & 0.1 & 0.0 & 0.1 & 1.0 & 0.3 & 1.5 & 0.9 & 0.4 \\
\hline $\begin{array}{l}\text { Drainage system } \\
\text { Public sewer }\end{array}$ & 89.8 & 37 & 96.8 & 64.6 & 93.1 & 52.6 & 37.2 & 76.5 & 13.5 & 42.8 & 62.5 \\
\hline Vault (bayara) & 5.4 & 28.5 & 1.5 & 9.4 & 0.8 & 13 & 37.6 & 14.4 & 51.7 & 46.0 & 17.3 \\
\hline Septic system & 4.3 & 28.4 & 1.2 & 21.9 & 6.1 & 28.5 & 20.7 & 8.0 & 28.4 & 9.0 & 16.8 \\
\hline Pipe connected to canal & 0.1 & 4.2 & 0.3 & 3.8 & 0.0 & 5.3 & 1.5 & 0.0 & 2.4 & 0.1 & 2.2 \\
\hline $\begin{array}{l}\text { Pipe connected to groun } \\
\text { water }\end{array}$ & 0.0 & 0.2 & 0.0 & 0.0 & 0.0 & 0.0 & 0.4 & 0.1 & 0.5 & 0.3 & 0.1 \\
\hline Emptied (no connection) & 0.2 & 0.9 & 0.0 & 0.2 & 0.0 & 0.3 & 1.3 & 0.5 & 1.8 & 0.7 & 0.5 \\
\hline Other/don't know & 0.1 & 0.2 & 0.1 & 0.1 & 0.0 & 0.2 & 0.2 & 0.2 & 0.2 & 0.1 & 0.2 \\
\hline No toilet facility & 0.1 & 0.7 & 0.0 & 0.1 & 0.0 & 0.1 & 1.0 & 0.3 & 1.5 & 0.9 & 0.4 \\
\hline \multicolumn{12}{|c|}{ Number of households using toilet } \\
\hline No facility & 0.1 & 0.7 & 0.0 & 0.1 & 0.0 & 0.1 & 1.0 & 0.3 & 1.5 & 0.9 & 0.4 \\
\hline One & 98.2 & 94.0 & 98.2 & 98.0 & 98.9 & 97.6 & 92.0 & 97.5 & 88.6 & 96.5 & 96.1 \\
\hline Two & 0.8 & 2.7 & 0.9 & 1.0 & 0.4 & 1.3 & 3.4 & 1.0 & 4.9 & 0.7 & 1.8 \\
\hline Three or more & 0.7 & 2.2 & 0.7 & 0.7 & 0.5 & 0.8 & 3.1 & 0.9 & 4.4 & 1.0 & 1.5 \\
\hline Not sure/missing & 0.2 & 0.4 & 0.2 & 0.2 & 0.2 & 0.2 & 0.5 & 0.3 & 0.6 & 0.9 & 0.3 \\
\hline \multicolumn{12}{|c|}{ Sanitation facility (WHO definition) } \\
\hline Improved $^{\mathrm{a}}$ & 97.7 & 88.5 & 97.7 & 93.8 & 98.8 & 91.7 & 88.5 & 96.6 & 83.6 & 94.7 & 92.9 \\
\hline Not improved & 2.3 & 11.5 & 2.3 & 6.2 & 1.2 & 8.3 & 11.5 & 3.4 & 16.4 & 5.3 & 7.1 \\
\hline Total households & 9,159 & $\mathbf{9 , 8 0 9}$ & 4,182 & 8,348 & 2,466 & 5,881 & 6,204 & 2,338 & 3,865 & 235 & 18,968 \\
\hline
\end{tabular}

${ }^{a}$ The household is considered to have improved sanitation facilities if it has sole use of a modern or traditional flush toilet that empties into a public sewer, vault (bayara), or septic system.

Source: Reproduced, with permission, from Table 2.7, El-Zanaty and Way (2009). 


\begin{tabular}{|c|c|c|}
\hline & $\begin{array}{r}\text { Incidence of } \\
\text { diarrhea (percent) }\end{array}$ & $\begin{array}{r}\text { Number of } \\
\text { children }\end{array}$ \\
\hline \multicolumn{3}{|l|}{ Age of child (months) } \\
\hline$<6$ & 12.67 & 1,137 \\
\hline $6-11$ & 18.69 & 1,310 \\
\hline $12-23$ & 11.35 & 2,202 \\
\hline$\underline{24-35}$ & 6.50 & 2,041 \\
\hline $36-47$ & 3.33 & 1,963 \\
\hline $48-59$ & 3.13 & 1,912 \\
\hline \multicolumn{3}{|l|}{ Sex of child } \\
\hline Male & 8.94 & 5,355 \\
\hline Female & 8.02 & 5,210 \\
\hline \multicolumn{3}{|l|}{ Region } \\
\hline Urban governorates & 9.50 & 1,659 \\
\hline Lower Egypt urban & 5.28 & 1,025 \\
\hline Lower Egypt rural & 6.00 & 3,585 \\
\hline Upper Egypt urban & 12.56 & 1,135 \\
\hline Upper Egypt rural & 10.56 & 3,011 \\
\hline Frontier governorates & 6.17 & 150 \\
\hline \multicolumn{3}{|l|}{ Wealth quintile } \\
\hline Lowest & 9.95 & 1,850 \\
\hline Second & 8.92 & 2,028 \\
\hline Third & 8.23 & 2,124 \\
\hline Fourth & 8.24 & 2,178 \\
\hline Highest & 7.39 & 2,206 \\
\hline \multicolumn{3}{|c|}{ Mother's schooling (years) } \\
\hline 0 & 7.70 & 2,764 \\
\hline $1-5$ & 11.88 & 946 \\
\hline $6-10$ & 9.25 & 1,325 \\
\hline $11+$ & 8.11 & 5,530 \\
\hline \multicolumn{3}{|c|}{ Father's schooling (years) } \\
\hline 0 & 7.03 & 1,710 \\
\hline $1-5$ & 10.13 & 1,257 \\
\hline $6-10$ & 9.17 & 1,643 \\
\hline $11+$ & 8.37 & 5,955 \\
\hline \multicolumn{3}{|l|}{ Mother's work status } \\
\hline Working & 8.60 & 9,262 \\
\hline Not working & 7.69 & 1,296 \\
\hline \multicolumn{3}{|l|}{ Dwelling type } \\
\hline House & 8.90 & 4,494 \\
\hline Apartment & 8.10 & 5,884 \\
\hline Other & 10.80 & 183 \\
\hline Total & 8.49 & 10,565 \\
\hline
\end{tabular}

Notes: Calculations use 2008 EDHS sample weights. Number of children does not sum to 10,565 on all variables due to missing values. 
Table 5 Incidence of diarrhea among children aged five years and younger in the two weeks prior to the 2008 EDHS survey, by water source

\begin{tabular}{|c|c|c|}
\hline & $\begin{array}{r}\text { Incidence of } \\
\text { diarrhea } \\
\text { (percent) }\end{array}$ & $\begin{array}{r}\text { Number of } \\
\text { children }\end{array}$ \\
\hline \multicolumn{3}{|l|}{ Water Source } \\
\hline Piped into dwelling & 8.28 & 8,968 \\
\hline Piped into yard/plot & 14.70 & 19 \\
\hline Public tap/standpipe & 14.89 & 270 \\
\hline Tubewell/borehole & 8.16 & 288 \\
\hline Protected well & 7.77 & 199 \\
\hline Protected spring & 0.00 & 3 \\
\hline Unprotected well & 0.00 & 0 \\
\hline Unprotected spring & 50.00 & 4 \\
\hline River/dam/lake/pond & 0.00 & 1 \\
\hline Tanker truck & 5.26 & 160 \\
\hline Cart with small tank & 9.08 & 76 \\
\hline Bottled water & 0.00 & 16 \\
\hline Other & 0.00 & 6 \\
\hline \multicolumn{3}{|c|}{ WHO definition of improved water } \\
\hline Improved & 8.52 & 10,317 \\
\hline Unimproved & 6.89 & 248 \\
\hline \multicolumn{3}{|c|}{ Improved-uninterrupted definition } \\
\hline Improved & 7.16 & 6,338 \\
\hline Unimproved & 10.47 & 4,226 \\
\hline \multicolumn{3}{|c|}{ Improved-uninterrupted trichotomous } \\
\hline Improved-uninterrupted & 7.16 & 6,338 \\
\hline Improved-interrupted & 10.87 & 3,140 \\
\hline Other & 9.32 & 1,086 \\
\hline \multicolumn{3}{|l|}{ Improved-unstored } \\
\hline Improved-unstored & 7.95 & 7,933 \\
\hline Improved-stored & 10.67 & 1,546 \\
\hline \multicolumn{3}{|l|}{ Water treatment } \\
\hline Treated & 10.02 & 449 \\
\hline Untreated & 8.42 & 10,116 \\
\hline Total & 8.49 & 10,565 \\
\hline
\end{tabular}


Table 6 Propensity score matching estimates for improved-uninterrupted definition of water, improved-uninterrupted versus all other cases

\begin{tabular}{lccccc}
\hline Method & $\begin{array}{c}\text { Mean } \\
\text { treatment }\end{array}$ & $\begin{array}{c}\text { Mean } \\
\text { control }\end{array}$ & \multicolumn{1}{c}{ ATT } & \multicolumn{1}{c}{ S.E. } & T-stat \\
\hline Naïve estimation & 0.079 & 0.113 & -0.034 & 0.006 & $-5.87^{* * *}$ \\
One-to-one matching & 0.079 & 0.106 & -0.027 & 0.010 & $-2.59^{* *}$ \\
Radius matching & 0.079 & 0.107 & -0.028 & 0.007 & $-4.11^{* * *}$ \\
Kernel matching & 0.079 & 0.107 & -0.028 & 0.007 & $-4.16^{* * *}$ \\
LLR matching & 0.079 & 0.109 & -0.029 & 0.007 & $-4.26^{* * *}$ \\
5 nearest neighbor matching & 0.079 & 0.106 & -0.027 & 0.008 & $-3.52^{* * *}$ \\
\hline
\end{tabular}

LLR $=$ Local linear regression.

Notes: Caliper $=0.03$ for all matching methods; 0 cases off support.

$\mathrm{N}$ treated $=6,254 ; \mathrm{N}$ control $=4,279$.

Significant at ${ }^{\wedge} \mathrm{p}<.10 ; * \mathrm{p}<.05 ; * * \mathrm{p}<.01 ; * * * \mathrm{p}<.001$.

Table 7 PSM matching estimates for improved-uninterrupted definition of water: Improveduninterrupted versus improved-interrupted

\begin{tabular}{|c|c|c|c|c|c|}
\hline Method & $\begin{array}{l}\text { Mean } \\
\text { treatment }\end{array}$ & $\begin{array}{l}\text { Mean } \\
\text { control }\end{array}$ & ATT & S.E. & T-stat \\
\hline Naïve estimation & 0.079 & 0.116 & -0.037 & 0.006 & $-5.91 * * *$ \\
\hline One-to-one matching & 0.079 & 0.107 & -0.028 & 0.011 & $-2.52 *$ \\
\hline Radius matching & 0.079 & 0.111 & -0.032 & 0.007 & $-4.44 * * *$ \\
\hline Kernel matching & 0.079 & 0.112 & -0.032 & 0.007 & $-4.51 * * *$ \\
\hline LLR matching & 0.079 & 0.111 & -0.031 & 0.007 & $-4.25 * * *$ \\
\hline 5 nearest neighbor matching & 0.079 & 0.107 & -0.028 & 0.008 & $-3.40 * * *$ \\
\hline
\end{tabular}

LLR $=$ Local linear regression.

Notes: Caliper $=0.03$ for all matching methods; 0 cases off support.

$\mathrm{N}$ treated $=6,254 ; \mathrm{N}$ control $=3,146$.

Significant at ${ }^{\wedge} \mathrm{p}<.10 ; * \mathrm{p}<.05 ; * * \mathrm{p}<.01 ; * * * \mathrm{p}<.001$.

Table 8 PSM matching estimates for improved-unstored definition of water: Improved-unstored versus improved-stored

\begin{tabular}{|c|c|c|c|c|c|}
\hline Method & $\begin{array}{l}\text { Mean } \\
\text { treatment }\end{array}$ & $\begin{array}{l}\text { Mean } \\
\text { control }\end{array}$ & ATT & S.E. & T-stat \\
\hline Naïve estimation & 0.087 & 0.114 & -0.027 & 0.008 & $-3.40 * * *$ \\
\hline One-to-one matching & 0.087 & 0.121 & -0.034 & 0.014 & $-2.34^{*}$ \\
\hline Radius matching & 0.087 & 0.117 & -0.030 & 0.009 & $-3.15^{* *}$ \\
\hline Kernel matching & 0.087 & 0.117 & -0.030 & 0.009 & $-3.22 * *$ \\
\hline LLR matching & 0.087 & 0.119 & -0.031 & 0.010 & $-3.12 * *$ \\
\hline 5 nearest neighbor matching & 0.087 & 0.112 & -0.025 & 0.010 & $-2.40 *$ \\
\hline
\end{tabular}

LLR $=$ Local linear regression.

Notes: Caliper $=0.03$ for all matching methods; 19 treated cases off support.

$\mathrm{N}$ treated $=7,814 ; \mathrm{N}$ control $=1,567$.

Significant at ${ }^{\wedge} \mathrm{p}<.10 ; *^{*}<.05 ; * * \mathrm{p}<.01 ; * * * \mathrm{p}<.001$. 
Table 9a PSM matching estimates for improved-uninterrupted definition of water: Improveduninterrupted versus all other cases

Children whose mothers have 0 years of education

\begin{tabular}{|c|c|c|c|c|c|}
\hline Method & $\begin{array}{l}\text { Mean } \\
\text { treatment }\end{array}$ & $\begin{array}{l}\text { Mean } \\
\text { control }\end{array}$ & ATT & S.E. & T-stat \\
\hline Naïve estimation & 0.062 & 0.105 & -0.042 & 0.010 & $-4.16^{* * *}$ \\
\hline One-to-one matching & 0.062 & 0.070 & -0.008 & 0.017 & -0.44 \\
\hline Radius matching & 0.062 & 0.103 & -0.041 & 0.011 & $-3.64 * * *$ \\
\hline Kernel matching & 0.062 & 0.103 & -0.041 & 0.011 & $-3.63 * * *$ \\
\hline LLR matching & 0.062 & 0.104 & -0.042 & 0.011 & $-3.72 * * *$ \\
\hline 5 nearest neighbor matching & 0.062 & 0.104 & -0.042 & 0.013 & $-3.30 * * *$ \\
\hline
\end{tabular}

LLR $=$ Local linear regression.

Notes: Caliper $=0.03$ for all matching methods; 5 treated cases off support.

$\mathrm{N}$ treated $=1,420 ; \mathrm{N}$ control $=1,555$.

Significant at ${ }^{\wedge} \mathrm{p}<.10 ; *_{\mathrm{p}}<.05 ; * * \mathrm{p}<.01 ; * * * \mathrm{p}<.001$.

Table 9b PSM matching estimates for improved-uninterrupted definition of water: Improveduninterrupted versus all other cases

Children whose mothers have 1-6 years of education

\begin{tabular}{llllll}
\hline Method & \multicolumn{2}{l}{$\begin{array}{l}\text { Mean } \\
\text { treatment }\end{array}$} & \multicolumn{1}{l}{$\begin{array}{l}\text { Mean } \\
\text { control }\end{array}$} & \multicolumn{1}{c}{ ATT } & \multicolumn{2}{c}{ S.E. } & T-stat \\
\hline Naïve estimation & 0.088 & 0.152 & -0.065 & 0.018 & $-3.52^{* * *}$ \\
One-to-one matching & 0.089 & 0.167 & -0.078 & 0.032 & $-2.43^{*}$ \\
Radius matching & 0.089 & 0.175 & -0.086 & 0.021 & $-4.15^{* * *}$ \\
Kernel matching & 0.089 & 0.176 & -0.087 & 0.021 & $-4.17^{* * *}$ \\
LLR matching & 0.089 & 0.178 & -0.089 & 0.021 & $-4.24^{* * *}$ \\
5 nearest neighbor matching & 0.089 & 0.186 & -0.098 & 0.023 & $-4.19^{* * *}$ \\
\hline
\end{tabular}

LLR = Local linear regression.

Notes: Caliper $=0.03$ for all matching methods; 7 treated cases off support.

$\mathrm{N}$ treated $=649 ; \mathrm{N}$ control $=584$.

Significant at ${ }^{\wedge} \mathrm{p}<.10 ;{ }^{*} \mathrm{p}<.05 ; * * \mathrm{p}<.01 ; * * * \mathrm{p}<.001$

Table 9c PSM matching estimates for improved-uninterrupted definition of water: Improveduninterrupted versus all other cases

Children whose mothers have 7 or more years of education

\begin{tabular}{lrrrrc}
\hline Method & \multicolumn{1}{l}{$\begin{array}{l}\text { Mean } \\
\text { treatment }\end{array}$} & \multicolumn{1}{l}{$\begin{array}{l}\text { Mean } \\
\text { control }\end{array}$} & \multicolumn{1}{c}{ ATT } & \multicolumn{1}{c}{ S.E. } & T-stat \\
\hline Naïve estimation & 0.084 & 0.108 & -0.024 & 0.008 & $-3.14^{* *}$ \\
One-to-one matching & 0.084 & 0.069 & 0.014 & 0.032 & 0.45 \\
Radius matching & 0.084 & 0.099 & -0.015 & 0.009 & $-1.73^{\wedge}$ \\
Kernel matching & 0.084 & 0.099 & -0.015 & 0.009 & $-1.74^{\wedge}$ \\
LLR matching & 0.084 & 0.100 & -0.016 & 0.009 & $-1.81^{\wedge}$ \\
5 nearest neighbor matching & 0.084 & 0.083 & 0.001 & 0.015 & 0.06 \\
\hline
\end{tabular}

LLR = Local linear regression.

Notes: Caliper $=0.03$ for all matching methods; 2 treated cases off support.

$\mathrm{N}$ treated $=4,188 ; \mathrm{N}$ control $=2,147$.

Significant at ${ }^{\wedge} \mathrm{p}<.10 ; * \mathrm{p}<.05 ; * * \mathrm{p}<.01 ; * * * \mathrm{p}<.001$. 
Table 10a PSM matching estimates for improved-uninterrupted definition of water: Improved-uninterrupted versus all other cases

Children residing in rural areas

\begin{tabular}{|c|c|c|c|c|c|}
\hline Method & $\begin{array}{l}\text { Mean } \\
\text { treatment }\end{array}$ & $\begin{array}{l}\text { Mean } \\
\text { control }\end{array}$ & ATT & S.E. & T-stat \\
\hline Naïve estimation & 0.070 & 0.113 & -0.043 & 0.007 & $-6.12 * * *$ \\
\hline One-to-one matching & 0.071 & 0.111 & -0.040 & 0.027 & -1.48 \\
\hline Radius matching & 0.071 & 0.106 & -0.035 & 0.008 & $-4.54 * * *$ \\
\hline Kernel matching & 0.071 & 0.107 & -0.036 & 0.008 & $-4.74 * * *$ \\
\hline $\begin{array}{l}\text { LLR matching } \\
5 \text { nearest neighbor }\end{array}$ & 0.071 & 0.106 & -0.035 & 0.008 & $-4.43 * * *$ \\
\hline matching & 0.071 & 0.094 & -0.024 & 0.013 & $-1.84^{\wedge}$ \\
\hline
\end{tabular}

LLR = Local linear regression.

Notes: Caliper $=0.03$ for all matching methods; 24 treated cases off support.

Significant at ${ }^{\wedge} \mathrm{p}<.10 ; * \mathrm{p}<.05 ; * * \mathrm{p}<.01 ; * * * \mathrm{p}<.001$.

Table 10b PSM matching estimates for improved-uninterrupted definition of water: Improved-uninterrupted versus all other cases

Children residing in urban areas

\begin{tabular}{|c|c|c|c|c|c|}
\hline Method & $\begin{array}{l}\text { Mean } \\
\text { treatment }\end{array}$ & $\begin{array}{l}\text { Mean } \\
\text { control }\end{array}$ & ATT & S.E. & T-stat \\
\hline Naïve estimation & 0.092 & 0.112 & -0.020 & 0.010 & $-1.99 *$ \\
\hline One-to-one matching & 0.092 & 0.119 & -0.027 & 0.027 & -1.01 \\
\hline Radius matching & 0.092 & 0.106 & -0.014 & 0.011 & -1.26 \\
\hline Kernel matching & 0.092 & 0.105 & -0.013 & 0.011 & -1.20 \\
\hline $\begin{array}{l}\text { LLR matching } \\
5 \text { nearest neighbor }\end{array}$ & 0.092 & 0.105 & -0.013 & 0.011 & -1.18 \\
\hline matching & 0.092 & 0.103 & -0.012 & 0.014 & -0.83 \\
\hline
\end{tabular}

LLR $=$ Local linear regression.

Notes: Caliper $=0.03$ for all matching methods; 0 cases off support.

Significant at ${ }^{\wedge} \mathrm{p}<.10 ; * \mathrm{p}<.05 ; * * \mathrm{p}<.01 ; * * * \mathrm{p}<.001$. 
Table 11 Incidence of diarrhea in the two weeks prior to the 2008 EDHS, children age five years and younger, by sanitation facility

\begin{tabular}{lrr}
\hline & $\begin{array}{l}\text { Incidence of } \\
\text { diarrhea (percent) }\end{array}$ & $\begin{array}{l}\text { Number of } \\
\text { children }\end{array}$ \\
Sanitation facility & 7.85 & 4,038 \\
Modern flush toilet & 13.00 & 266 \\
Traditional tank flush toilet & 8.55 & 5,618 \\
Traditional bucket flush toilet & 8.12 & 35 \\
Pit latrine & 0.00 & 4 \\
Bucket toilet & 15.80 & 39 \\
No facility & 14.56 & 6 \\
Other & & \\
WHO definition of improved sanitation & 8.40 & 9,537 \\
$\quad$ Improved & 9.26 & 1,028 \\
$\quad$ Unimproved & 8.85 & \\
Improved-connected definition & 8.10 & 5,414 \\
$\quad$ Improved & $\mathbf{8 . 4 9}$ & 5,151 \\
$\quad$ Unimproved & & $\mathbf{1 0 , 5 6 5}$ \\
\hline Total & & \\
\hline Notes: Calculations use DHS sample weights. Number of children does not sum & \\
to 10,565 on all variables due to missing values. The detailed water source & & \\
variable is coded only for legal residents. &
\end{tabular}

Table 12 PSM matching estimates for improved-connected definition of sanitation: Improvedconnected versus all other cases

\begin{tabular}{|c|c|c|c|c|c|}
\hline Method & $\begin{array}{l}\text { Mean } \\
\text { treatment }\end{array}$ & $\begin{array}{l}\text { Mean } \\
\text { control }\end{array}$ & ATT & S.E. & T-stat \\
\hline Naïve estimation & 0.093 & 0.093 & 0.001 & 0.006 & 0.11 \\
\hline One-to-one matching & 0.094 & 0.066 & 0.028 & 0.025 & 1.12 \\
\hline Radius matching & 0.094 & 0.067 & 0.026 & 0.014 & $1.89^{\wedge}$ \\
\hline Kernel matching & 0.094 & 0.066 & 0.028 & 0.014 & $2.06^{*}$ \\
\hline LLR matching & 0.094 & 0.063 & 0.030 & 0.016 & $1.91^{\wedge}$ \\
\hline 5 nearest neighbor matching & 0.094 & 0.053 & 0.040 & 0.015 & $2.62 * *$ \\
\hline
\end{tabular}

LLR = Local linear regression.

Notes: Caliper $=0.03$ for all matching methods; 21 treated cases off support.

$\mathrm{N}$ treated $=4,811 ; \mathrm{N}$ control $=5,729$.

Significant at $\wedge^{\wedge}<.10 ; * \mathrm{p}<.05 ; * * \mathrm{p}<.01 ; * * * \mathrm{p}<.001$. 


\begin{tabular}{|c|c|c|c|c|c|}
\hline Method & $\begin{array}{l}\text { Mean } \\
\text { treatment }\end{array}$ & $\begin{array}{l}\text { Mean } \\
\text { control }\end{array}$ & ATT & S.E. & T-stat \\
\hline Naïve estimation & 0.094 & 0.091 & 0.002 & 0.010 & 0.24 \\
\hline One-to-one matching & 0.093 & 0.071 & 0.022 & 0.035 & 0.63 \\
\hline Radius matching & 0.093 & 0.061 & 0.032 & 0.021 & 1.49 \\
\hline Kernel matching & 0.093 & 0.061 & 0.032 & 0.021 & 1.51 \\
\hline LLR matching & 0.093 & 0.062 & 0.031 & 0.025 & 1.25 \\
\hline 5 nearest neighbor matching & 0.093 & 0.064 & 0.029 & 0.026 & 1.12 \\
\hline
\end{tabular}

LLR $=$ Local linear regression.

Notes: Caliper $=0.03$ for all matching methods; 225 treated cases off support.

$\mathrm{N}$ treated $=3,726 ; \mathrm{N}$ control $=1,100$.

Significant at ${ }^{\wedge} \mathrm{p}<.10 ; * \mathrm{p}<.05 ; * * \mathrm{p}<.01 ; * * * \mathrm{p}<.001$.

Table 14 PSM matching estimates for improved-connected definition of sanitation: Improvedconnected versus all other cases

Children whose mothers have 0 years of education

\begin{tabular}{|c|c|c|c|c|c|}
\hline Method & $\begin{array}{l}\text { Mean } \\
\text { Treatment }\end{array}$ & $\begin{array}{l}\text { Mean } \\
\text { Control } \\
\end{array}$ & ATT & S.E. & T-stat \\
\hline Naïve estimation & 0.087 & 0.084 & 0.004 & 0.012 & 0.30 \\
\hline One-to-one matching & 0.087 & 0.080 & 0.008 & 0.036 & 0.22 \\
\hline Radius matching & 0.087 & 0.052 & 0.035 & 0.021 & $1.70^{\wedge}$ \\
\hline Kernel matching & 0.087 & 0.052 & 0.035 & 0.021 & $1.70^{\wedge}$ \\
\hline LLR matching & 0.087 & 0.051 & 0.036 & 0.021 & $1.69^{\wedge}$ \\
\hline 5 nearest neighbor matching & 0.087 & 0.046 & 0.042 & 0.021 & $1.96^{*}$ \\
\hline
\end{tabular}

LLR = Local linear regression.

Note: Caliper $=0.03$ for all matching methods; 119 treated cases off support.

$\mathrm{N}$ treated $=652 ; \mathrm{N}$ control $=2,328$.

Significant at ${ }^{\wedge} \mathrm{p}<.10 ; * \mathrm{p}<.05 ; * * \mathrm{p}<.01 ; * * * \mathrm{p}<.001$. 
Table 15a PSM matching estimates for improved-connected definition of sanitation: Improved-connected versus all other cases

Children residing in rural areas

\begin{tabular}{lrrrrl}
\hline Method & \multicolumn{1}{l}{$\begin{array}{l}\text { Mean } \\
\text { treatment }\end{array}$} & $\begin{array}{l}\text { Mean } \\
\text { control }\end{array}$ & \multicolumn{1}{c}{ ATT } & \multicolumn{1}{l}{ S.E. } & T-stat \\
\hline Naïve estimation & 0.089 & 0.090 & -0.001 & 0.008 & -0.17 \\
One-to-one matching & 0.089 & 0.061 & 0.028 & 0.023 & 1.23 \\
Radius matching & 0.089 & 0.054 & 0.034 & 0.010 & $3.58 * * *$ \\
Kernel matching & 0.089 & 0.055 & 0.034 & 0.010 & $3.50^{* * *}$ \\
LLR matching & 0.089 & 0.056 & 0.033 & 0.010 & $3.42^{* * *}$ \\
5 nearest neighbor matching & 0.089 & 0.058 & 0.031 & 0.012 & $2.53 *$ \\
\hline
\end{tabular}

LLR $=$ Local linear regression.

Note: Caliper $=0.03$ for all matching methods; 2 treated cases off support.

Significant at ${ }^{\wedge} \mathrm{p}<.10 ;{ }^{*} \mathrm{p}<.05 ; * * \mathrm{p}<.01 ; * * * \mathrm{p}<.001$.

Table 15b PSM matching estimates for improved-connected definition of sanitation: Improved-connected versus all other cases

Children residing in urban areas

\begin{tabular}{lrrrrl}
\hline Method & \multicolumn{1}{l}{$\begin{array}{l}\text { Mean } \\
\text { treatment }\end{array}$} & $\begin{array}{l}\text { Mean } \\
\text { control }\end{array}$ & \multicolumn{1}{c}{ ATT } & \multicolumn{1}{l}{ S.E. } & T-stat \\
\hline Naïve estimation & 0.096 & 0.108 & -0.012 & 0.012 & -1.02 \\
One-to-one matching & 0.096 & 0.081 & 0.015 & 0.035 & 0.42 \\
Radius matching & 0.096 & 0.075 & 0.021 & 0.023 & 0.88 \\
Kernel matching & 0.096 & 0.073 & 0.022 & 0.023 & 0.98 \\
LLR matching & 0.096 & 0.065 & 0.031 & 0.026 & 1.18 \\
5 nearest neighbor matching & 0.096 & 0.061 & 0.035 & 0.025 & 1.38 \\
\hline
\end{tabular}

LLR = Local linear regression.

Notes: Caliper $=0.03$ for all matching methods; 38 treated cases off support.

Significant at ${ }^{\wedge} \mathrm{p}<.10 ; * \mathrm{p}<.05 ; * * \mathrm{p}<.01 ; * * * \mathrm{p}<.001$. 


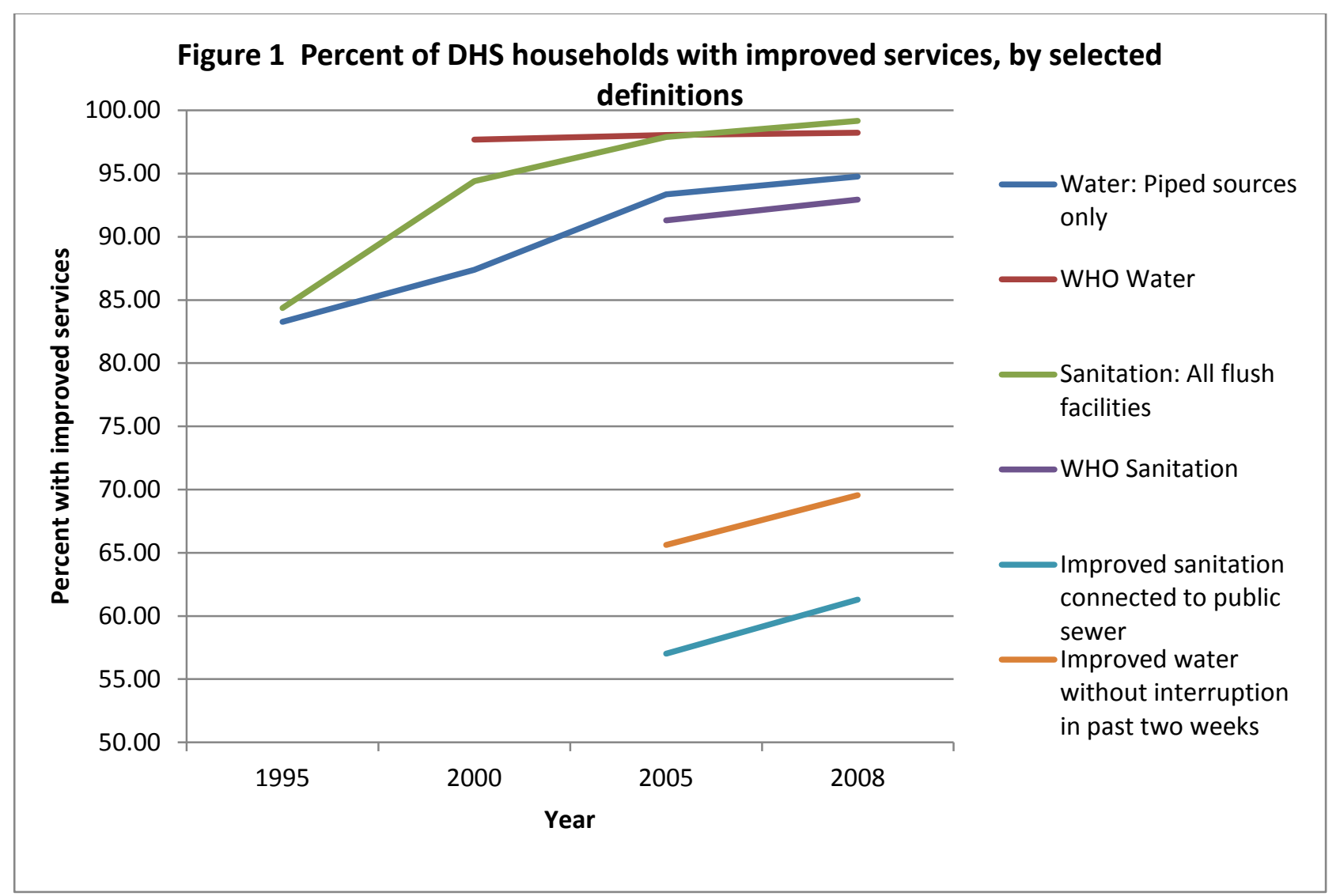

Note: Figures are weighted with the respective survey year sample weights.

Source: EDHS surveys 1995, 2000, 2005, and 2008. 
Figure 2

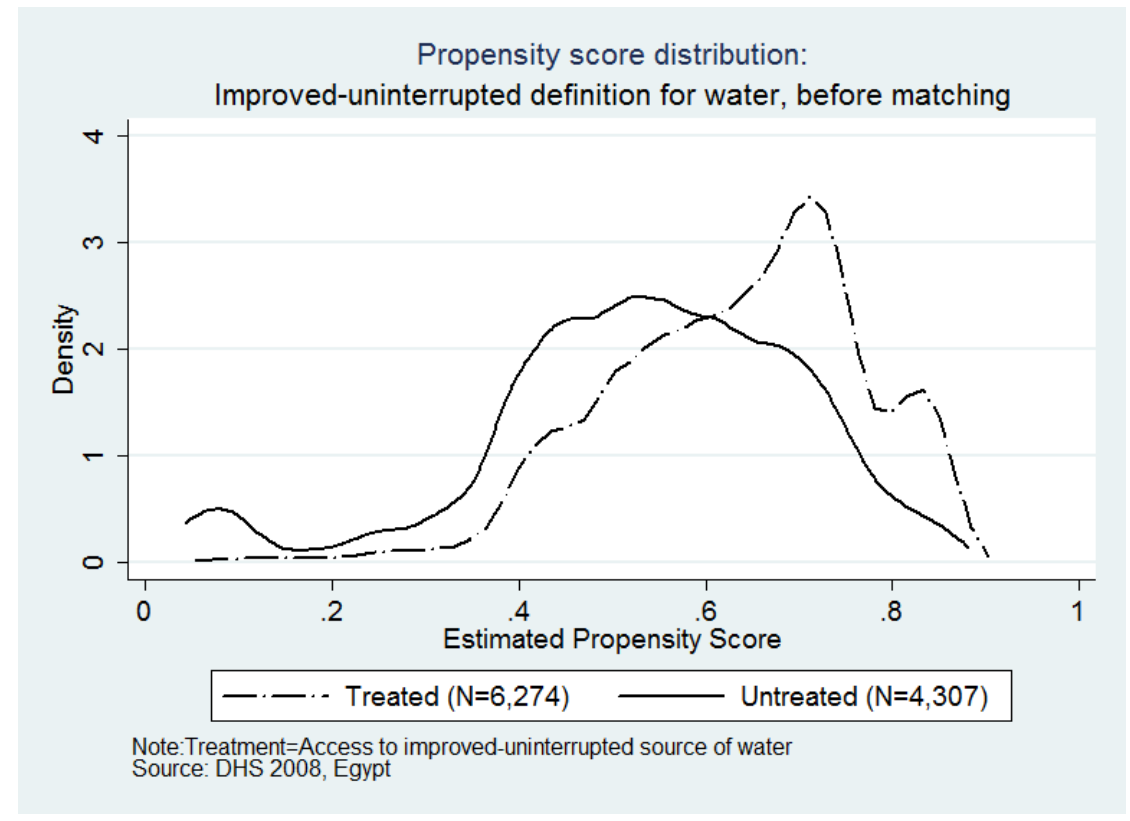

Propensity score distribution:

Improved-uninterrupted definition for water, after matching

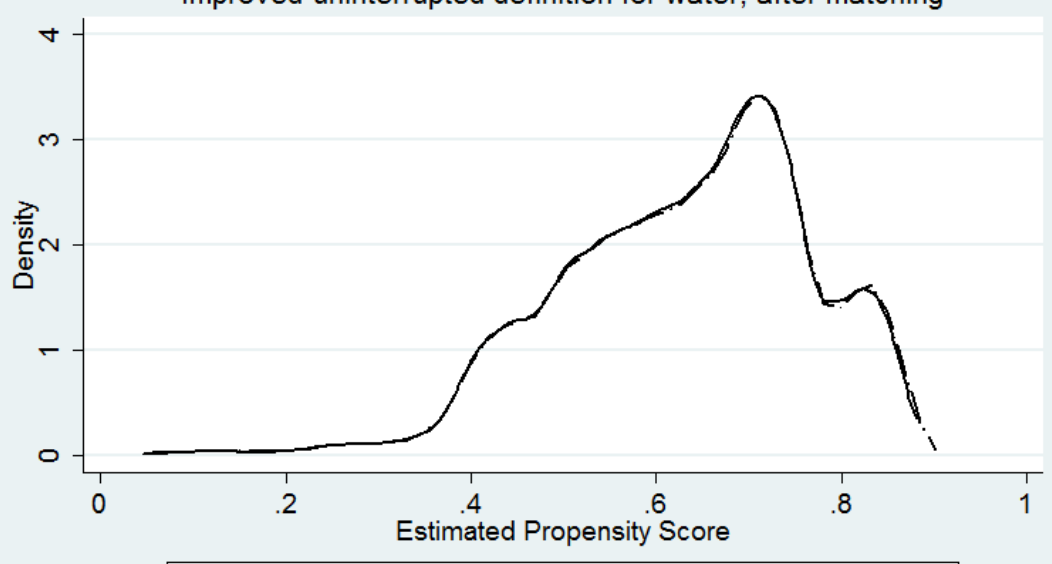

- - - Treated $(\mathrm{N}=6,254) \quad$ Untreated $(\mathrm{N}=4,279)$

Note: Radius matching (caliper $=0.03$ ); Treatment=Access to improved-uninterrupted source of water Source: DHS 2008, Egypt 


\section{Figure 3}
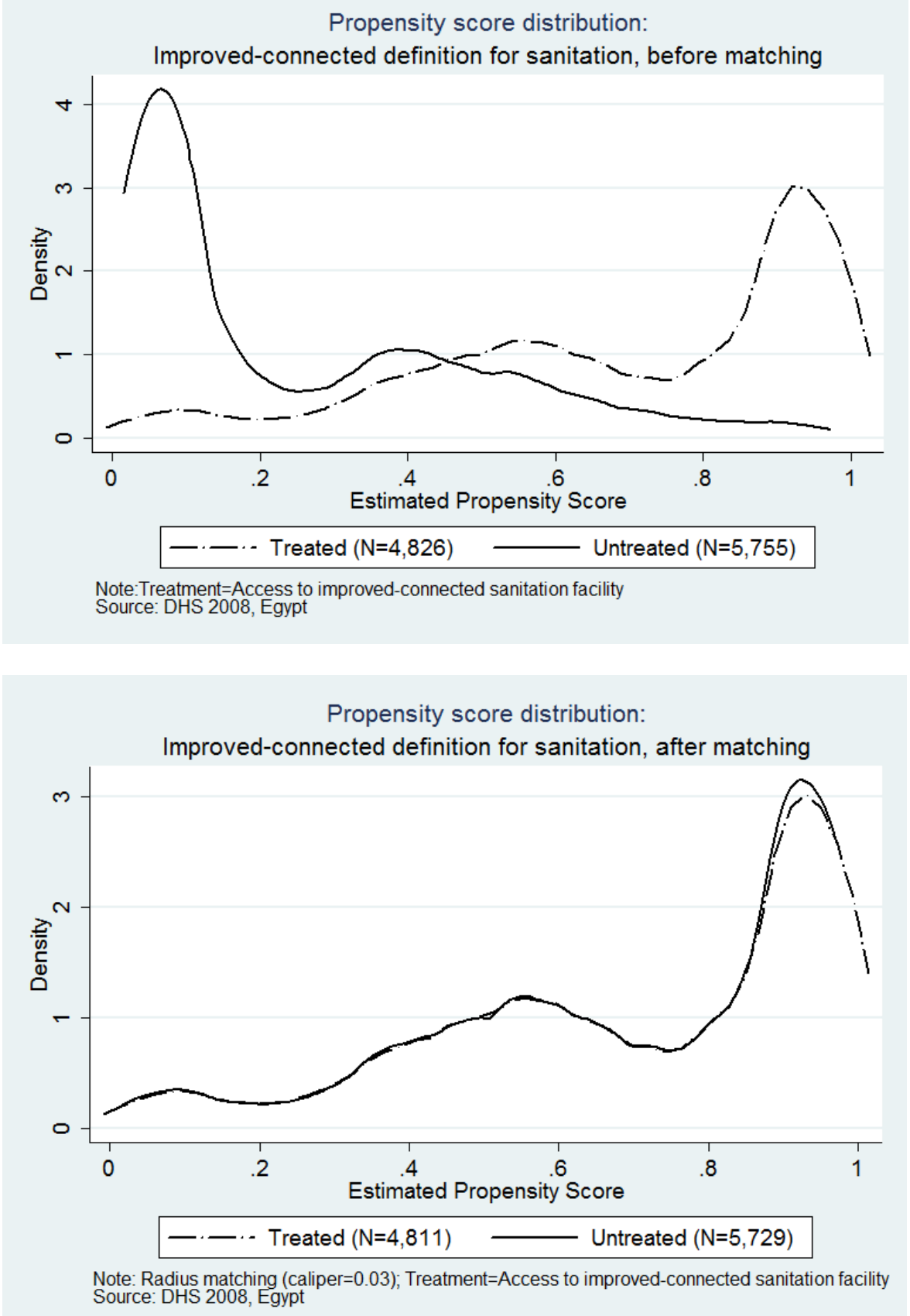


\section{APPENDIX 1}

Table A1 Characteristics of the qualitative study population

\begin{tabular}{|c|c|c|c|c|c|c|c|c|}
\hline \multicolumn{9}{|c|}{ Sixth of October } \\
\hline \multicolumn{3}{|c|}{$\begin{array}{r}\text { Husband } \\
\end{array}$} & \multicolumn{2}{|r|}{ Wife } & \multicolumn{2}{|r|}{ Sons } & \multicolumn{2}{|c|}{ Daughters } \\
\hline Age & Education & Profession & Age & Education & Age & Education & Age & Education \\
\hline 61 & Preparatory & Retired & 58 & Illiterate & $\begin{array}{l}28 \\
24 \\
10\end{array}$ & $\begin{array}{l}\text { University } \\
\text { Diploma } \\
\text { Primary }\end{array}$ & $\begin{array}{l}21 \\
16\end{array}$ & $\begin{array}{l}\text { Diploma } \\
\text { Secondary }\end{array}$ \\
\hline 30 & University & Merchant & 28 & University $^{1}$ & 1 & N/A & - & - \\
\hline \multicolumn{9}{|c|}{ Qaliubeya } \\
\hline 42 & $\mathrm{PhD}$ & $\begin{array}{l}\text { University } \\
\text { professor }\end{array}$ & 34 & University & $\begin{array}{c}16 \\
13 \\
7\end{array}$ & $\begin{array}{l}\text { Secondary } \\
\text { Preparatory } \\
\text { Primary }\end{array}$ & 6 & Primary \\
\hline 30 & Diploma $^{2}$ & Univ. employee & 27 & Illiterate & 9,6 & Primary & 1 & N/A \\
\hline 30 & Primary & Univ. employee & 23 & Diploma & 3,1 & N/A & 6 & Primary \\
\hline \multicolumn{9}{|c|}{ Menufiya } \\
\hline 41 & Literate $^{3}$ & Mechanic & 35 & Illiterate & 10 & Primary & 16,12 & $\begin{array}{l}\text { Preparatory, } \\
\text { Primary }\end{array}$ \\
\hline 41 & Literate & Grocer & 35 & Illiterate & $\begin{array}{l}26 \\
22 \\
20 \\
18 \\
\end{array}$ & Diplomas & $\begin{array}{l}18 \\
16,12\end{array}$ & $\begin{array}{l}\text { Secondary, } \\
\text { Preparatory }\end{array}$ \\
\hline 51 & Literate & Mosque janitor & 37 & Illiterate & 17 & Secondary & $\begin{array}{l}20 \\
18 \\
12 \\
10,6\end{array}$ & $\begin{array}{l}\text { Diploma, } \\
\text { Secondary } \\
\text { Preparatory } \\
\text { Primary }\end{array}$ \\
\hline 45 & Literate & $\begin{array}{l}\text { Agriculture Co- } \\
\text { op Employee }\end{array}$ & 36 & Illiterate & $\begin{array}{c}20 \\
15 \\
11 \\
6\end{array}$ & $\begin{array}{l}\text { University } \\
\text { Secondary } \\
\text { Primary }\end{array}$ & - & - \\
\hline
\end{tabular}

N/A = Not applicable.

\footnotetext{
${ }^{1}$ Of all women interviewed for the study, only this one is employed. She works at the local health clinic. The remainder of the women are housewives.

${ }^{2}$ A diploma is a post-secondary certificate obtained from a technical, commercial, or other educational institute.

3 "Literate" is defined as the ability to read and write. For the purpose of this study, a person defined as literate does not have any education certificates.
} 
Table A2 Drinking water service delivery in qualitative study households

\begin{tabular}{|c|c|c|c|c|c|c|c|c|}
\hline $\begin{array}{c}\text { Govern- } \\
\text { orate }\end{array}$ & $\begin{array}{c}\text { Household } \\
\text { number }\end{array}$ & $\begin{array}{c}\text { Drinkin } \\
\text { g water } \\
\text { source }\end{array}$ & $\begin{array}{c}\text { Date of } \\
\text { install- } \\
\text { ation }\end{array}$ & $\begin{array}{l}\text { Date of } \\
\text { rehab- } \\
\text { itation }\end{array}$ & $\begin{array}{c}\text { Service } \\
\text { provider }\end{array}$ & $\begin{array}{l}\text { Cost of } \\
\text { conne- } \\
\text { ction }^{4}\end{array}$ & $\begin{array}{c}\text { Perception } \\
\text { of water } \\
\text { quantity }\end{array}$ & $\begin{array}{c}\text { Perception } \\
\text { of water } \\
\text { quality }\end{array}$ \\
\hline \multirow[t]{2}{*}{$\begin{array}{l}\text { Sixth of } \\
\text { October }\end{array}$} & HH 1 & $\begin{array}{l}\text { Surface } \\
\text { (Nile) }\end{array}$ & 2000 & N/A & $\begin{array}{l}\text { American/ } \\
\text { French } \\
\text { project }\end{array}$ & LE 55 & Good & Poor \\
\hline & HH 2 & Surface & 2006 & N/A & $\begin{array}{l}\text { American/ } \\
\text { French } \\
\text { project }\end{array}$ & LE 75 & Adequate & Poor \\
\hline \multirow[t]{3}{*}{$\begin{array}{l}\text { Qaliub- } \\
\text { eya }\end{array}$} & HH 1 & $\begin{array}{l}\text { Artesian } \\
\text { well }\end{array}$ & $1960 \mathrm{~s}$ & 2000 & $\begin{array}{l}\text { MHUUD } \\
\text { (through } \\
\text { Local } \\
\text { Unit) }\end{array}$ & N/A & Poor & Poor \\
\hline & HH 2 & $\begin{array}{l}\text { Artesian } \\
\text { well }\end{array}$ & $\begin{array}{l}\text { Don't } \\
\text { know }\end{array}$ & 1990 & Local Unit & N/A & Adequate & Poor \\
\hline & HH 3 & $\begin{array}{l}\text { Artesian } \\
\text { well }\end{array}$ & $1950 \mathrm{~s}$ & 1995 & Local Unit & N/A & Adequate & Poor \\
\hline \multirow[t]{4}{*}{$\begin{array}{l}\text { Menuf- } \\
\text { iya }\end{array}$} & HH1 & $\begin{array}{l}\text { Artesian } \\
\text { well }\end{array}$ & 2008 & N/A & $\begin{array}{l}\text { Shrouk } \\
\text { program }\end{array}$ & LE 50 & Adequate & Poor \\
\hline & $\mathrm{HH} 2$ & $\begin{array}{l}\text { Artesian } \\
\text { well }\end{array}$ & 2008 & N/A & $\begin{array}{l}\text { Shrouk } \\
\text { program }\end{array}$ & $\begin{array}{l}\text { LE } 35+ \\
\text { (LE } 5 \text { per } \\
\text { meter of } \\
\text { pipes) }\end{array}$ & Adequate & Poor \\
\hline & HH3 & $\begin{array}{l}\text { Artesian } \\
\text { well }\end{array}$ & 2008 & N/A & $\begin{array}{l}\text { Shrouk } \\
\text { program }\end{array}$ & LE 50 & Poor & Poor \\
\hline & $\mathrm{HH} 4$ & $\begin{array}{l}\text { Artesian } \\
\text { well }\end{array}$ & 2004 & N/A & $\begin{array}{l}\text { Don't } \\
\text { know }\end{array}$ & $\begin{array}{l}\text { LE } 40+ \\
\text { (LE } 3 \text { per } \\
\text { meter of } \\
\text { pipes) }\end{array}$ & Adequate & Poor \\
\hline
\end{tabular}

N/A = Not applicable.

Note: US\$1.00 = 5.6 LE in May 2010 .

\footnotetext{
${ }^{4}$ Cost of connection includes cost of meter installation and installation of tertiary pipe to connect household to main network.
} 
Table A3: Sanitation service delivery in qualitative study households

\begin{tabular}{|c|c|c|c|c|c|}
\hline Governorate & $\begin{array}{l}\text { Village/ } \\
\text { household } \\
\text { number }\end{array}$ & $\begin{array}{l}\text { Date of } \\
\text { installation }\end{array}$ & $\begin{array}{l}\text { Service } \\
\text { provider }\end{array}$ & $\begin{array}{l}\text { Cost of } \\
\text { connection }\end{array}$ & $\begin{array}{l}\text { Perception of } \\
\text { service } \\
\text { delivery }\end{array}$ \\
\hline \multirow[t]{2}{*}{ Sixth of October } & HH 1 & 2000 & $\begin{array}{l}\text { American/ } \\
\text { French } \\
\text { project }\end{array}$ & $\begin{array}{l}\text { Don't } \\
\text { remember }\end{array}$ & Good \\
\hline & НH 2 & 2006 & $\begin{array}{l}\text { American/ } \\
\text { French } \\
\text { project }\end{array}$ & LE 60 & Good \\
\hline \multirow[t]{3}{*}{ Qaliubeya } & HH 1 & 2004 & $\begin{array}{l}\text { MHUUD } \\
\text { (through } \\
\text { local unit) }\end{array}$ & $\begin{array}{l}\text { Don't } \\
\text { remember }\end{array}$ & Good \\
\hline & $\mathrm{HH} 2$ & 2000 & Local Unit & LE 55 & Adequate \\
\hline & HH 3 & 2002 & Local Unit & LE 60 & Good \\
\hline \multirow[t]{4}{*}{ Menufiya } & HH1 & N/A & $\begin{array}{l}\text { Not } \\
\text { improved }\end{array}$ & N/A & Good \\
\hline & $\mathrm{HH} 2$ & N/A & $\begin{array}{l}\text { Not } \\
\text { improved }\end{array}$ & N/A & Poor \\
\hline & HH3 & N/A & $\begin{array}{l}\text { Not } \\
\text { improved }\end{array}$ & N/A & Poor \\
\hline & HH4 & N/A & $\begin{array}{l}\text { Network } \\
\text { under } \\
\text { construction }\end{array}$ & N/A & Poor \\
\hline
\end{tabular}

N/A = Not applicable

Note: US $\$ 1.00=5.6$ LE in May 2010 .

Table A4 PSM matching estimates for WHO definition of improved water

\begin{tabular}{lrrrrr}
\hline Method & Mean treatment & Mean control & \multicolumn{3}{c}{ TT } \\
AT & S.E. & stat \\
\hline Naïve estimation & 0.087 & 0.069 & 0.019 & 0.018 & 1.06 \\
One-to-one matching & 0.090 & 0.057 & 0.034 & 0.027 & 1.26 \\
Radius matching & 0.090 & 0.068 & 0.022 & 0.020 & 1.11 \\
Kernel matching & 0.090 & 0.069 & 0.021 & 0.020 & 1.05 \\
LLR matching & 0.090 & 0.074 & 0.017 & 0.021 & 0.78 \\
5 nearest neighbor matching & 0.090 & 0.076 & 0.014 & 0.023 & 0.64 \\
\hline
\end{tabular}

Note: Caliper $=0.03$ for all matching methods; 1,832 treated cases off support.

$\mathrm{N}$ treated $=262 ; \mathrm{N}$ control $=7,210$.

Significant at ${ }^{\wedge} \mathrm{p}<.10 ; * \mathrm{p}<.05 ; * * \mathrm{p}<.01 ; * * * \mathrm{p}<.001$ 


\begin{tabular}{|c|c|c|c|c|c|}
\hline \multirow[b]{2}{*}{ Variable } & \multirow[b]{2}{*}{ Sample } & \multicolumn{2}{|c|}{ Mean } & \multicolumn{2}{|c|}{ T-test } \\
\hline & & Treated & Control & T-stat & $\mathbf{p}>|\mathbf{t}|$ \\
\hline \multirow[t]{2}{*}{ Lower Egypt urban } & Unmatched & 0.087 & 0.004 & 4.83 & 0.000 \\
\hline & Matched & 0.007 & 0.009 & -0.93 & 0.350 \\
\hline \multirow[t]{2}{*}{ Lower Egypt rural } & Unmatched & 0.280 & 0.212 & 2.48 & 0.013 \\
\hline & Matched & 0.399 & 0.354 & 5.64 & 0.000 \\
\hline \multirow[t]{2}{*}{ Upper Egypt urban } & Unmatched & 0.120 & 0.000 & 6.04 & 0.000 \\
\hline & Matched & 0.000 & 0.000 & & . \\
\hline \multirow[t]{2}{*}{ Upper Egypt rural } & Unmatched & 0.333 & 0.323 & 0.33 & 0.739 \\
\hline & Matched & 0.474 & 0.538 & -7.66 & 0.000 \\
\hline \multirow[t]{2}{*}{ Frontier governorates } & Unmatched & 0.048 & 0.450 & -28.79 & 0.000 \\
\hline & Matched & 0.068 & 0.058 & 2.50 & 0.012 \\
\hline \multirow[t]{2}{*}{ Second wealth quintile } & Unmatched & 0.195 & 0.241 & -1.89 & 0.059 \\
\hline & Matched & 0.246 & 0.293 & -6.46 & 0.000 \\
\hline \multirow[t]{2}{*}{ Third wealth quintile } & Unmatched & 0.195 & 0.245 & -2.03 & 0.042 \\
\hline & Matched & 0.235 & 0.247 & -1.77 & 0.077 \\
\hline \multirow[t]{2}{*}{ Fourth wealth quintile } & Unmatched & 0.199 & 0.100 & 4.02 & 0.000 \\
\hline & Matched & 0.167 & 0.129 & 6.41 & 0.000 \\
\hline \multirow[t]{2}{*}{ Highest wealth quintile } & Unmatched & 0.201 & 0.037 & 6.68 & 0.000 \\
\hline & Matched & 0.082 & 0.116 & -6.89 & 0.000 \\
\hline \multirow[t]{2}{*}{ Mother's education } & Unmatched & 7.600 & 4.253 & 9.73 & 0.000 \\
\hline & Matched & 6.339 & 5.921 & 4.76 & 0.000 \\
\hline \multirow[t]{2}{*}{ Father's education } & Unmatched & 8.892 & 6.914 & 5.95 & 0.000 \\
\hline & Matched & 8.048 & 7.880 & 1.85 & 0.065 \\
\hline \multirow[t]{2}{*}{ Dwelling (house) } & Unmatched & 0.462 & 0.647 & -6.01 & 0.000 \\
\hline & Matched & 0.580 & 0.543 & 4.46 & 0.000 \\
\hline \multirow[t]{2}{*}{ Dwelling (apartment) } & Unmatched & 0.520 & 0.323 & 6.40 & 0.000 \\
\hline & Matched & 0.399 & 0.447 & -5.80 & 0.000 \\
\hline \multirow[t]{2}{*}{ Household head age (squared) } & Unmatched & 1834.400 & 1841.100 & -0.09 & 0.927 \\
\hline & Matched & 1889.600 & 1699.900 & 9.32 & 0.000 \\
\hline \multirow[t]{2}{*}{ Mother employed } & Unmatched & 0.124 & 0.074 & 2.45 & 0.014 \\
\hline & Matched & 0.104 & 0.115 & -2.11 & 0.035 \\
\hline
\end{tabular}

Notes: Balance statistics are given for 5-nearest neighbor matching (0.03 caliper). There were no observations in the control group in urban Upper Egypt under this definition. 


\section{Figure A1}

Propensity score distribution:

WHO definition for improved water, before matching

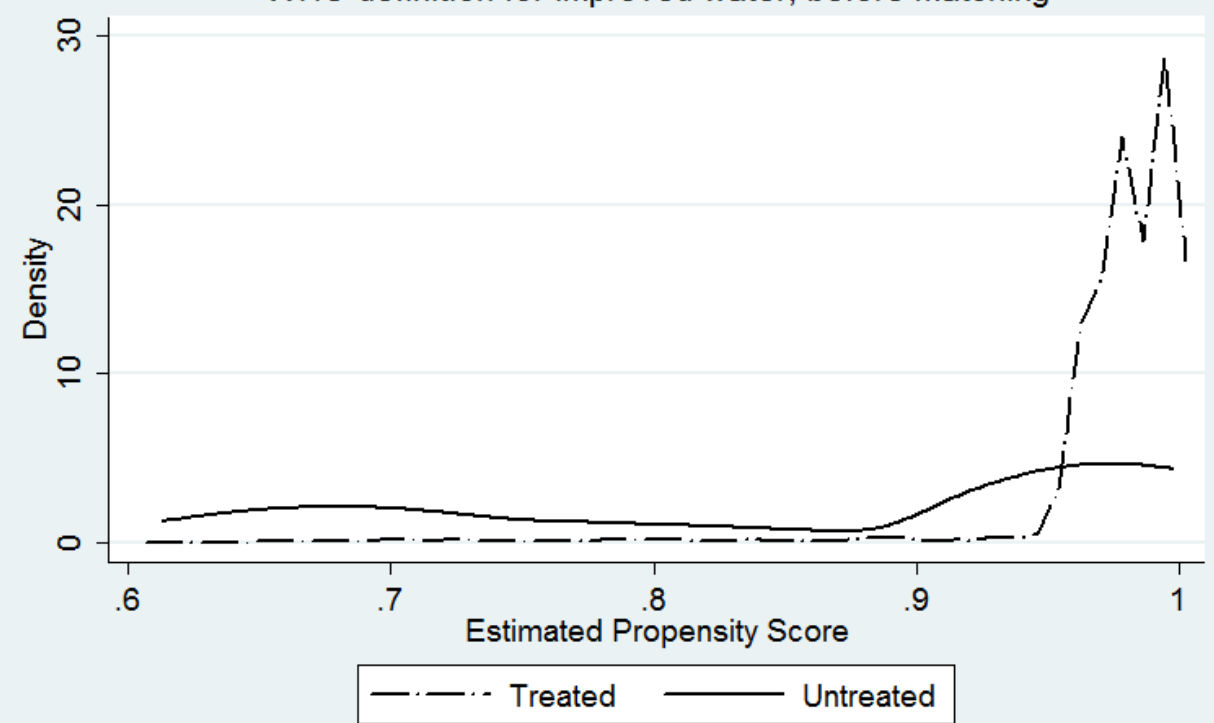

Note:Treatment=Access to improved source of water

Propensity score distribution:

WHO definition for improved water, after matching

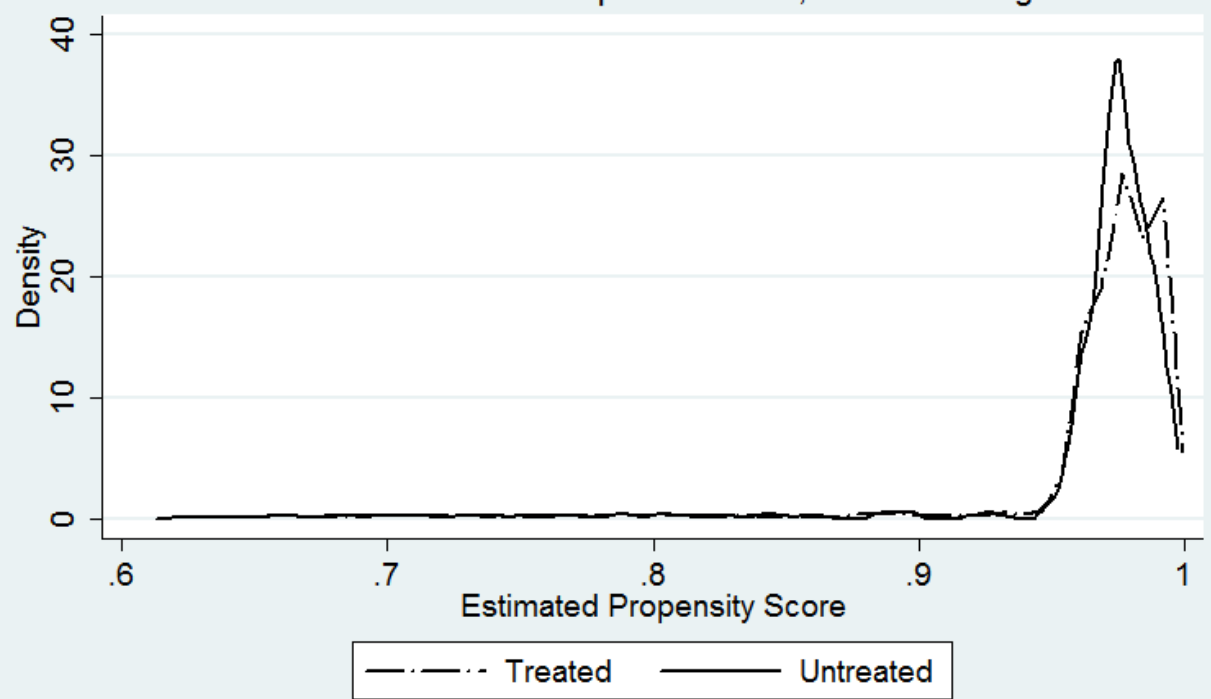

Note: Radius matching (caliper $=0.03$ ); Treatment=Access to improved source of water Source: DHS 2008, Egypt 


\begin{tabular}{|c|c|c|c|c|c|}
\hline \multirow[b]{2}{*}{ Variable } & \multirow[b]{2}{*}{ Sample } & \multicolumn{2}{|c|}{ Mean } & \multicolumn{2}{|c|}{ T-test } \\
\hline & & Treated & Control & T-stat & $\mathbf{p}>|\mathbf{t}|$ \\
\hline \multirow[t]{2}{*}{ Lower Egypt urban } & Unmatched & 0.095 & 0.068 & 4.88 & 0.000 \\
\hline & Matched & 0.095 & 0.098 & -0.42 & 0.676 \\
\hline \multirow[t]{2}{*}{ Lower Egypt rural } & Unmatched & 0.288 & 0.266 & 2.49 & 0.013 \\
\hline & Matched & 0.288 & 0.285 & 0.30 & 0.761 \\
\hline \multirow[t]{2}{*}{ Upper Egypt urban } & Unmatched & 0.131 & 0.095 & 5.68 & 0.000 \\
\hline & Matched & 0.131 & 0.128 & 0.45 & 0.651 \\
\hline \multirow[t]{2}{*}{ Upper Egypt rural } & Unmatched & 0.289 & 0.396 & -11.51 & 0.000 \\
\hline & Matched & 0.290 & 0.295 & -0.70 & 0.484 \\
\hline \multirow[t]{2}{*}{ Frontier governorates } & Unmatched & 0.022 & 0.112 & -19.89 & 0.000 \\
\hline & Matched & 0.021 & 0.020 & 0.34 & 0.735 \\
\hline \multirow[t]{2}{*}{ Lowest wealth quintile } & Unmatched & 0.141 & 0.279 & -17.81 & 0.000 \\
\hline & Matched & 0.140 & 0.141 & -0.07 & 0.943 \\
\hline \multirow[t]{2}{*}{ Second wealth quintile } & Unmatched & 0.182 & 0.218 & -4.52 & 0.000 \\
\hline & Matched & 0.182 & 0.181 & 0.15 & 0.878 \\
\hline \multirow[t]{2}{*}{ Third wealth quintile } & Unmatched & 0.195 & 0.199 & -0.49 & 0.621 \\
\hline & Matched & 0.195 & 0.195 & 0.13 & 0.899 \\
\hline \multirow[t]{2}{*}{ Fourth wealth quintile } & Unmatched & 0.224 & 0.157 & 8.56 & 0.000 \\
\hline & Matched & 0.224 & 0.236 & -1.63 & 0.104 \\
\hline \multirow[t]{2}{*}{ Mother's education } & Unmatched & 8.392 & 6.237 & 19.81 & 0.000 \\
\hline & Matched & 8.396 & 8.339 & 0.58 & 0.559 \\
\hline \multirow[t]{2}{*}{ Father's education } & Unmatched & 9.435 & 7.977 & 13.82 & 0.000 \\
\hline & Matched & 9.436 & 9.360 & 0.81 & 0.419 \\
\hline \multirow[t]{2}{*}{ Dwelling (house) } & Unmatched & 0.409 & 0.550 & -14.40 & 0.000 \\
\hline & Matched & 0.410 & 0.414 & -0.49 & 0.621 \\
\hline \multirow[t]{2}{*}{ Dwelling (apartment) } & Unmatched & 0.573 & 0.432 & 14.42 & 0.000 \\
\hline & Matched & 0.573 & 0.570 & 0.31 & 0.759 \\
\hline \multirow[t]{2}{*}{ Mother's educ. * Father's educ. } & Unmatched & 97.958 & 68.360 & 18.49 & 0.000 \\
\hline & Matched & 97.944 & 97.176 & 0.52 & 0.605 \\
\hline \multirow[t]{2}{*}{ Mother employed } & Unmatched & 0.125 & 0.119 & 0.94 & 0.348 \\
\hline & Matched & 0.125 & 0.115 & 1.77 & 0.078 \\
\hline \multirow[t]{2}{*}{ Upper Egypt rural poor } & Unmatched & 0.185 & 0.277 & -11.14 & 0.000 \\
\hline & Matched & 0.185 & 0.192 & -0.99 & 0.324 \\
\hline \multirow[t]{2}{*}{ Rural poor } & Unmatched & 0.269 & 0.432 & -17.72 & 0.000 \\
\hline & Matched & 0.269 & 0.273 & -0.49 & 0.626 \\
\hline \multirow[t]{2}{*}{ Frontier poor } & Unmatched & 0.003 & 0.050 & -16.32 & 0.000 \\
\hline & Matched & 0.003 & 0.003 & -0.16 & 0.876 \\
\hline
\end{tabular}

Note: Balance statistics are given for 5-nearest neighbor matching ( 0.03 caliper). 
Table A7 Balance statistics for improved-uninterrupted definition of water: Improveduninterrupted versus improved-interrupted

\begin{tabular}{|c|c|c|c|c|c|}
\hline \multirow[b]{2}{*}{ Variable } & & \multicolumn{2}{|c|}{ Mean } & \multicolumn{2}{|c|}{ T-test } \\
\hline & Sample & $\begin{array}{c}\text { Treate } \\
\text { d }\end{array}$ & Control & T-stat & $\mathbf{p}>|\mathbf{t}|$ \\
\hline \multirow[t]{2}{*}{ Lower Egypt urban } & Unmatched & 0.095 & 0.085 & 1.69 & 0.091 \\
\hline & Matched & 0.095 & 0.093 & 0.47 & 0.637 \\
\hline \multirow[t]{2}{*}{ Lower Egypt rural } & Unmatched & 0.288 & 0.253 & 3.52 & 0.000 \\
\hline & Matched & 0.288 & 0.291 & -0.34 & 0.734 \\
\hline \multirow[t]{2}{*}{ Upper Egypt urban } & Unmatched & 0.131 & 0.118 & 1.84 & 0.066 \\
\hline & Matched & 0.131 & 0.122 & 1.58 & 0.113 \\
\hline \multirow[t]{2}{*}{ Upper Egypt rural } & Unmatched & 0.289 & 0.379 & -8.86 & 0.000 \\
\hline & Matched & 0.290 & 0.292 & -0.26 & 0.798 \\
\hline \multirow[t]{2}{*}{ Frontier governorates } & Unmatched & 0.022 & 0.082 & -13.92 & 0.000 \\
\hline & Matched & 0.021 & 0.021 & 0.04 & 0.970 \\
\hline \multirow[t]{2}{*}{ Lowest wealth quintile } & Unmatched & 0.141 & 0.217 & -9.43 & 0.000 \\
\hline & Matched & 0.140 & 0.147 & -1.12 & 0.262 \\
\hline \multirow[t]{2}{*}{ Second wealth quintile } & Unmatched & 0.182 & 0.211 & -3.35 & 0.001 \\
\hline & Matched & 0.182 & 0.183 & -0.06 & 0.952 \\
\hline \multirow[t]{2}{*}{ Third wealth quintile } & Unmatched & 0.195 & 0.208 & -1.43 & 0.152 \\
\hline & Matched & 0.195 & 0.194 & 0.15 & 0.878 \\
\hline \multirow[t]{2}{*}{ Fourth wealth quintile } & Unmatched & 0.224 & 0.187 & 4.17 & 0.000 \\
\hline & Matched & 0.224 & 0.222 & 0.30 & 0.767 \\
\hline \multirow[t]{2}{*}{ Mother's education } & Unmatched & 8.392 & 7.095 & 10.85 & 0.000 \\
\hline & Matched & 8.396 & 8.328 & 0.70 & 0.484 \\
\hline \multirow[t]{2}{*}{ Father's education } & Unmatched & 9.435 & 8.632 & 6.96 & 0.000 \\
\hline & Matched & 9.436 & 9.402 & 0.36 & 0.716 \\
\hline \multirow[t]{2}{*}{ Dwelling (house) } & Unmatched & 0.573 & 0.487 & 7.94 & 0.000 \\
\hline & Matched & 0.573 & 0.566 & 0.74 & 0.461 \\
\hline \multirow[t]{2}{*}{ Dwelling (apartment) } & Unmatched & 0.409 & 0.499 & -8.29 & 0.000 \\
\hline & Matched & 0.410 & 0.416 & -0.75 & 0.452 \\
\hline \multirow[t]{2}{*}{ Household head age (squared) } & Unmatched & 1806.30 & 1852.900 & -1.81 & 0.070 \\
\hline & Matched & 1806.70 & 1813.700 & -0.34 & 0.737 \\
\hline \multirow[t]{2}{*}{ Lower Egypt rural poor } & Unmatched & 0.082 & 0.102 & -3.25 & 0.001 \\
\hline & Matched & 0.082 & 0.087 & -1.08 & 0.280 \\
\hline \multirow[t]{2}{*}{ Frontier poor } & Unmatched & 0.003 & 0.021 & -8.56 & 0.000 \\
\hline & Matched & 0.003 & 0.002 & 0.77 & 0.439 \\
\hline \multirow[t]{2}{*}{ Mother's educ. * Father's educ. } & Unmatched & 97.958 & 79.607 & 10.25 & 0.000 \\
\hline & Matched & 97.944 & 97.880 & 0.04 & 0.966 \\
\hline \multirow[t]{2}{*}{ Dwelling (urban apartment) } & Unmatched & 0.342 & 0.258 & 8.34 & 0.000 \\
\hline & Matched & 0.342 & 0.338 & 0.45 & 0.656 \\
\hline \multirow[t]{2}{*}{ Mother employed } & Unmatched & 0.125 & 0.120 & 0.73 & 0.465 \\
\hline & Matched & 0.125 & 0.132 & -1.08 & 0.278 \\
\hline
\end{tabular}

Note: Balance statistics are given for 5-nearest neighbor matching ( 0.03 caliper). 
Table A8 Balance statistics for improved-unstored definition of water: Improved-unstored versus improved-stored

\begin{tabular}{|c|c|c|c|c|c|}
\hline \multirow[b]{3}{*}{ Variable } & & \multicolumn{2}{|c|}{ Mean } & \multicolumn{2}{|c|}{ T-test } \\
\hline & & Treate & & & \\
\hline & Sample & d & Control & T-stat & $\mathbf{p}>|\mathbf{t}|$ \\
\hline \multirow[t]{2}{*}{ Lower Egypt urban } & Unmatched & 0.101 & 0.047 & 6.77 & 0.000 \\
\hline & Matched & 0.099 & 0.105 & -1.24 & 0.214 \\
\hline \multirow[t]{2}{*}{ Lower Egypt rural } & Unmatched & 0.133 & 0.096 & 4.05 & 0.000 \\
\hline & Matched & 0.283 & 0.271 & 1.63 & 0.102 \\
\hline \multirow[t]{2}{*}{ Upper Egypt urban } & Unmatched & 0.133 & 0.096 & 4.05 & 0.000 \\
\hline & Matched & 0.133 & 0.132 & 0.27 & 0.784 \\
\hline \multirow[t]{2}{*}{ Upper Egypt rural } & Unmatched & 0.306 & 0.386 & -6.23 & 0.000 \\
\hline & Matched & 0.307 & 0.318 & -1.56 & 0.118 \\
\hline \multirow[t]{2}{*}{ Frontier governorates } & Unmatched & 0.025 & 0.125 & -18.46 & 0.000 \\
\hline & Matched & 0.025 & 0.025 & 0.00 & 1.000 \\
\hline \multirow[t]{2}{*}{ Lowest wealth quintile } & Unmatched & 0.153 & 0.230 & -7.44 & 0.000 \\
\hline & Matched & 0.153 & 0.156 & -0.45 & 0.655 \\
\hline \multirow[t]{2}{*}{ Second wealth quintile } & Unmatched & 0.188 & 0.211 & -2.09 & 0.037 \\
\hline & Matched & 0.189 & 0.179 & 1.62 & 0.104 \\
\hline \multirow[t]{2}{*}{ Third wealth quintile } & Unmatched & 0.201 & 0.192 & 0.85 & 0.397 \\
\hline & Matched & 0.201 & 0.217 & -2.46 & 0.014 \\
\hline \multirow[t]{2}{*}{ Fourth wealth quintile } & Unmatched & 0.216 & 0.187 & 2.59 & 0.010 \\
\hline & Matched & 0.216 & 0.225 & -1.30 & 0.195 \\
\hline \multirow[t]{2}{*}{ Mother's education } & Unmatched & 8.142 & 7.038 & 7.27 & 0.000 \\
\hline & Matched & 8.134 & 7.951 & 2.09 & 0.037 \\
\hline \multirow[t]{2}{*}{ Father's Education } & Unmatched & 9.270 & 8.645 & 4.28 & 0.000 \\
\hline & Matched & 9.261 & 8.987 & 3.20 & 0.001 \\
\hline \multirow[t]{2}{*}{ Dwelling (house) } & Unmatched & 0.561 & 0.460 & 7.34 & 0.000 \\
\hline & Matched & 0.560 & 0.561 & -0.08 & 0.938 \\
\hline \multirow[t]{2}{*}{ Dwelling (apartment) } & Unmatched & 0.422 & 0.527 & -7.71 & 0.000 \\
\hline & Matched & 0.422 & 0.424 & -0.18 & 0.859 \\
\hline \multirow[t]{2}{*}{ Upper Egypt rural poor } & Unmatched & 0.196 & 0.257 & -5.43 & 0.000 \\
\hline & Matched & 0.197 & 0.202 & -0.90 & 0.368 \\
\hline \multirow[t]{3}{*}{ Mother Edu * Father Edu } & Unmatched & 94.378 & 78.994 & 6.77 & 0.000 \\
\hline & Matched & 94.115 & 91.203 & 2.23 & 0.026 \\
\hline & & 1826.0 & 1801.70 & & \\
\hline \multirow[t]{3}{*}{ Household head age (squared) } & Unmatched & 00 & 0 & 0.75 & 0.456 \\
\hline & & 1822.6 & 1832.20 & & \\
\hline & Matched & 00 & 0 & -0.50 & 0.619 \\
\hline \multirow[t]{2}{*}{ Mother Employed } & Unmatched & 0.127 & 0.107 & 2.12 & 0.034 \\
\hline & Matched & 0.126 & 0.122 & 0.82 & 0.415 \\
\hline
\end{tabular}

Note: Balance statistics are given for 5-nearest neighbor matching ( 0.03 caliper). 
Table A9a Balance statistics for improved-uninterrupted definition for water: Mothers with 0 years of education

\begin{tabular}{|c|c|c|c|c|c|}
\hline \multirow[b]{2}{*}{ Variable } & \multirow[b]{2}{*}{ Sample } & \multicolumn{2}{|c|}{ Mean } & \multicolumn{2}{|c|}{ T-test } \\
\hline & & Treated & Control & T-stat & $\mathbf{p}>|\mathbf{t}|$ \\
\hline \multirow[t]{2}{*}{ Lower Egypt urban } & Unmatched & 0.020 & 0.017 & 0.61 & 0.539 \\
\hline & Matched & 0.020 & 0.018 & 0.25 & 0.805 \\
\hline \multirow[t]{2}{*}{ Lower Egypt rural } & Unmatched & 0.211 & 0.190 & 1.44 & 0.151 \\
\hline & Matched & 0.211 & 0.221 & -0.63 & 0.529 \\
\hline \multirow[t]{2}{*}{ Upper Egypt urban } & Unmatched & 0.103 & 0.072 & 3.05 & 0.002 \\
\hline & Matched & 0.104 & 0.101 & 0.19 & 0.853 \\
\hline \multirow[t]{2}{*}{ Upper Egypt rural } & Unmatched & 0.557 & 0.570 & -0.69 & 0.489 \\
\hline & Matched & 0.559 & 0.564 & -0.27 & 0.785 \\
\hline \multirow[t]{2}{*}{ Frontier governorates } & Unmatched & 0.018 & 0.126 & -11.49 & 0.000 \\
\hline & Matched & 0.018 & 0.014 & 0.92 & 0.356 \\
\hline \multirow[t]{2}{*}{ Lowest wealth quintile } & Unmatched & 0.367 & 0.522 & -8.66 & 0.000 \\
\hline & Matched & 0.366 & 0.383 & -0.94 & 0.348 \\
\hline \multirow[t]{2}{*}{ Second wealth quintile } & Unmatched & 0.303 & 0.257 & 2.83 & 0.005 \\
\hline & Matched & 0.305 & 0.305 & -0.03 & 0.974 \\
\hline \multirow[t]{2}{*}{ Third wealth quintile } & Unmatched & 0.174 & 0.140 & 2.54 & 0.011 \\
\hline & Matched & 0.175 & 0.169 & 0.42 & 0.677 \\
\hline \multirow[t]{2}{*}{ Fourth wealth quintile } & Unmatched & 0.111 & 0.053 & 5.82 & 0.000 \\
\hline & Matched & 0.108 & 0.103 & 0.43 & 0.669 \\
\hline \multirow[t]{2}{*}{ Father's Education } & Unmatched & 4.541 & 4.451 & 0.51 & 0.609 \\
\hline & Matched & 4.546 & 4.353 & 1.07 & 0.284 \\
\hline \multirow[t]{2}{*}{ Dwelling (house) } & Unmatched & 0.287 & 0.210 & 4.89 & 0.000 \\
\hline & Matched & 0.287 & 0.302 & -0.92 & 0.357 \\
\hline \multirow[t]{2}{*}{ Dwelling (apartment) } & Unmatched & 0.666 & 0.753 & -5.29 & 0.000 \\
\hline & Matched & 0.668 & 0.664 & 0.22 & 0.824 \\
\hline \multirow[t]{2}{*}{ Upper Egypt rural poor } & Unmatched & 0.446 & 0.484 & -2.06 & 0.040 \\
\hline & Matched & 0.448 & 0.466 & -0.97 & 0.331 \\
\hline \multirow[t]{2}{*}{ Rural poor } & Unmatched & 0.574 & 0.690 & -6.66 & 0.000 \\
\hline & Matched & 0.575 & 0.599 & -1.32 & 0.187 \\
\hline \multirow[t]{2}{*}{ Frontier poor } & Unmatched & 0.004 & 0.091 & -11.13 & 0.000 \\
\hline & Matched & 0.004 & 0.004 & 0.00 & 1.000 \\
\hline \multirow[t]{2}{*}{ Mother employed } & Unmatched & 0.052 & 0.097 & -4.65 & 0.000 \\
\hline & Matched & 0.052 & 0.044 & 0.98 & 0.327 \\
\hline
\end{tabular}

Note: Balance statistics are given for 5-nearest neighbor matching ( 0.03 caliper). 
Table A9b Balance statistics for improved-uninterrupted definition of water: Mothers with 1-6 years of education

\begin{tabular}{|c|c|c|c|c|c|}
\hline \multirow[b]{2}{*}{ Variable } & \multirow[b]{2}{*}{ Sample } & \multicolumn{2}{|c|}{ Mean } & \multicolumn{2}{|c|}{ T-test } \\
\hline & & Treated & Control & T-stat & $\mathbf{p}>|\mathbf{t}|$ \\
\hline \multirow[t]{2}{*}{ Lower Egypt urban } & Unmatched & 0.068 & 0.041 & 2.06 & 0.040 \\
\hline & Matched & 0.069 & 0.083 & -0.97 & 0.332 \\
\hline \multirow[t]{2}{*}{ Lower Egypt rural } & Unmatched & 0.282 & 0.307 & -0.99 & 0.324 \\
\hline & Matched & 0.283 & 0.260 & 0.94 & 0.347 \\
\hline \multirow[t]{2}{*}{ Upper Egypt urban } & Unmatched & 0.092 & 0.079 & 0.87 & 0.387 \\
\hline & Matched & 0.093 & 0.083 & 0.65 & 0.517 \\
\hline \multirow[t]{2}{*}{ Upper Egypt rural } & Unmatched & 0.332 & 0.382 & -1.83 & 0.067 \\
\hline & Matched & 0.336 & 0.369 & -1.23 & 0.220 \\
\hline \multirow[t]{2}{*}{ Frontier governorates } & Unmatched & 0.032 & 0.113 & -5.58 & 0.000 \\
\hline & Matched & 0.033 & 0.033 & 0.00 & 1.000 \\
\hline \multirow[t]{2}{*}{ Lowest wealth quintile } & Unmatched & 0.178 & 0.305 & -5.28 & 0.000 \\
\hline & Matched & 0.181 & 0.188 & -0.35 & 0.730 \\
\hline \multirow[t]{2}{*}{ Second wealth quintile } & Unmatched & 0.254 & 0.280 & -1.03 & 0.302 \\
\hline & Matched & 0.257 & 0.263 & -0.25 & 0.799 \\
\hline \multirow[t]{2}{*}{ Third wealth quintile } & Unmatched & 0.251 & 0.239 & 0.48 & 0.629 \\
\hline & Matched & 0.252 & 0.237 & 0.64 & 0.525 \\
\hline \multirow[t]{2}{*}{ Fourth wealth quintile } & Unmatched & 0.225 & 0.121 & 4.81 & 0.000 \\
\hline & Matched & 0.217 & 0.232 & -0.68 & 0.495 \\
\hline \multirow[t]{2}{*}{ Father's education } & Unmatched & 6.471 & 6.366 & 0.40 & 0.687 \\
\hline & Matched & 6.502 & 6.738 & -0.93 & 0.352 \\
\hline \multirow[t]{2}{*}{ Dwelling (house) } & Unmatched & 0.460 & 0.384 & 2.71 & 0.007 \\
\hline & Matched & 0.463 & 0.469 & -0.21 & 0.832 \\
\hline \multirow[t]{2}{*}{ Dwelling (apartment) } & Unmatched & 0.512 & 0.597 & -3.01 & 0.003 \\
\hline & Matched & 0.509 & 0.512 & -0.09 & 0.929 \\
\hline \multirow[t]{2}{*}{ Upper Egypt rural poor } & Unmatched & 0.208 & 0.275 & -2.76 & 0.006 \\
\hline & Matched & 0.210 & 0.221 & -0.46 & 0.645 \\
\hline \multirow[t]{2}{*}{ Rural poor } & Unmatched & 0.329 & 0.495 & -6.00 & 0.000 \\
\hline & Matched & 0.333 & 0.349 & -0.60 & 0.549 \\
\hline \multirow[t]{2}{*}{ Frontier poor } & Unmatched & 0.008 & 0.068 & -5.75 & 0.000 \\
\hline & Matched & 0.008 & 0.015 & -1.21 & 0.226 \\
\hline \multirow[t]{2}{*}{ Mother employed } & Unmatched & 0.051 & 0.092 & -2.84 & 0.005 \\
\hline & Matched & 0.050 & 0.074 & -1.76 & 0.079 \\
\hline
\end{tabular}

Note: Balance statistics are given for 5-nearest neighbor matching ( 0.03 caliper). 
Table A9c: Balance statistics for improved-uninterrupted definition for water: Mothers with 7 or more years of education

\begin{tabular}{|c|c|c|c|c|c|}
\hline \multirow[b]{2}{*}{ Variable } & \multirow[b]{2}{*}{ Sample } & \multicolumn{2}{|c|}{ Mean } & \multicolumn{2}{|c|}{ T-test } \\
\hline & & Treated & Control & T-stat & $\mathbf{p}>|\mathbf{t}|$ \\
\hline \multirow[t]{2}{*}{ Lower Egypt urban } & Unmatched & 0.125 & 0.114 & 1.35 & 0.177 \\
\hline & Matched & 0.126 & 0.118 & 1.05 & 0.294 \\
\hline \multirow[t]{2}{*}{ Lower Egypt rural } & Unmatched & 0.315 & 0.309 & 0.46 & 0.648 \\
\hline & Matched & 0.315 & 0.324 & -0.91 & 0.363 \\
\hline \multirow[t]{2}{*}{ Upper Egypt urban } & Unmatched & 0.147 & 0.117 & 3.29 & 0.001 \\
\hline & Matched & 0.147 & 0.133 & 1.78 & 0.075 \\
\hline \multirow[t]{2}{*}{ Upper Egypt rural } & Unmatched & 0.192 & 0.274 & -7.52 & 0.000 \\
\hline & Matched & 0.192 & 0.207 & -1.76 & 0.078 \\
\hline \multirow[t]{2}{*}{ Frontier governorates } & Unmatched & 0.021 & 0.102 & -14.41 & 0.000 \\
\hline & Matched & 0.021 & 0.021 & 0.00 & 1.000 \\
\hline \multirow[t]{2}{*}{ Lowest wealth quintile } & Unmatched & 0.058 & 0.094 & -5.41 & 0.000 \\
\hline & Matched & 0.058 & 0.057 & 0.24 & 0.814 \\
\hline \multirow[t]{2}{*}{ Second wealth quintile } & Unmatched & 0.130 & 0.172 & -4.57 & 0.000 \\
\hline & Matched & 0.130 & 0.118 & 1.60 & 0.110 \\
\hline \multirow[t]{2}{*}{ Third wealth quintile } & Unmatched & 0.194 & 0.231 & -3.46 & 0.001 \\
\hline & Matched & 0.194 & 0.210 & -1.79 & 0.074 \\
\hline \multirow[t]{2}{*}{ Fourth wealth quintile } & Unmatched & 0.262 & 0.242 & 1.77 & 0.077 \\
\hline & Matched & 0.262 & 0.264 & -0.14 & 0.886 \\
\hline \multirow[t]{2}{*}{ Father's education } & Unmatched & 11.558 & 10.974 & 5.38 & 0.000 \\
\hline & Matched & 11.553 & 11.612 & -0.67 & 0.503 \\
\hline \multirow[t]{2}{*}{ Dwelling (house) } & Unmatched & 0.688 & 0.606 & 6.56 & 0.000 \\
\hline & Matched & 0.688 & 0.693 & -0.43 & 0.664 \\
\hline \multirow[t]{2}{*}{ Dwelling (apartment) } & Unmatched & 0.306 & 0.390 & -6.73 & 0.000 \\
\hline & Matched & 0.306 & 0.300 & 0.59 & 0.552 \\
\hline \multirow[t]{2}{*}{ Rural poor } & Unmatched & 0.155 & 0.227 & -7.05 & 0.000 \\
\hline & Matched & 0.155 & 0.155 & -0.01 & 0.995 \\
\hline
\end{tabular}

Note: Balance statistics are given for 5-nearest neighbor matching ( 0.03 caliper). 
Table A10a Balance statistics for improved-uninterrupted definition of water: Children residing in rural areas

\begin{tabular}{|c|c|c|c|c|c|}
\hline \multirow[b]{2}{*}{ Variable } & \multirow[b]{2}{*}{ Sample } & \multicolumn{2}{|c|}{ Mean } & \multicolumn{2}{|c|}{ T-test } \\
\hline & & Treated & Control & T-stat & $\mathbf{p}>|\mathbf{t}|$ \\
\hline \multirow[t]{2}{*}{ Lower Egypt rural } & Unmatched & 0.494 & 0.375 & 9.86 & 0.000 \\
\hline & Matched & 0.490 & 0.488 & 0.17 & 0.866 \\
\hline \multirow[t]{2}{*}{ Upper Egypt rural } & Unmatched & 0.497 & 0.559 & -5.06 & 0.000 \\
\hline & Matched & 0.500 & 0.502 & -0.16 & 0.877 \\
\hline \multirow[t]{2}{*}{ Frontier governorates } & Unmatched & 0.010 & 0.067 & 12.74 & 0.000 \\
\hline & Matched & 0.010 & 0.010 & -0.07 & 0.943 \\
\hline \multirow[t]{2}{*}{ Lowest wealth quintile } & Unmatched & 0.213 & 0.351 & 12.80 & 0.000 \\
\hline & Matched & 0.213 & 0.213 & 0.07 & 0.945 \\
\hline \multirow[t]{2}{*}{ Second wealth quintile } & Unmatched & 0.249 & 0.258 & -0.88 & 0.378 \\
\hline & Matched & 0.251 & 0.256 & -0.56 & 0.574 \\
\hline \multirow[t]{2}{*}{ Third wealth quintile } & Unmatched & 0.226 & 0.207 & 1.85 & 0.065 \\
\hline & Matched & 0.227 & 0.236 & -0.83 & 0.407 \\
\hline \multirow[t]{2}{*}{ Fourth wealth quintile } & Unmatched & 0.197 & 0.117 & 8.88 & 0.000 \\
\hline & Matched & 0.197 & 0.181 & 1.66 & 0.097 \\
\hline \multirow[t]{2}{*}{ Mother's education } & Unmatched & 7.115 & 5.225 & 14.34 & 0.000 \\
\hline & Matched & 7.075 & 7.133 & -0.45 & 0.654 \\
\hline \multirow[t]{2}{*}{ Father's education } & Unmatched & 8.541 & 7.323 & 9.29 & 0.000 \\
\hline & Matched & 8.519 & 8.639 & -0.97 & 0.334 \\
\hline \multirow[t]{2}{*}{ Dwelling (house) } & Unmatched & 0.585 & 0.660 & -6.32 & 0.000 \\
\hline & Matched & 0.584 & 0.590 & -0.48 & 0.633 \\
\hline \multirow[t]{2}{*}{ Dwelling (apartment) } & Unmatched & 0.396 & 0.318 & 6.63 & 0.000 \\
\hline & Matched & 0.398 & 0.398 & 0.00 & 0.996 \\
\hline \multirow[t]{2}{*}{ Upper Egypt rural poor } & Unmatched & 0.318 & 0.390 & -6.16 & 0.000 \\
\hline & Matched & 0.320 & 0.320 & -0.02 & 0.988 \\
\hline \multirow[t]{2}{*}{ Rural poor } & Unmatched & 0.461 & 0.609 & 12.22 & 0.000 \\
\hline & Matched & 0.464 & 0.469 & -0.43 & 0.665 \\
\hline \multirow[t]{2}{*}{ Frontier poor } & Unmatched & 0.002 & 0.050 & $\begin{array}{r}- \\
12.76\end{array}$ & 0.000 \\
\hline & Matched & 0.002 & 0.002 & 0.14 & 0.886 \\
\hline
\end{tabular}

Note: Balance statistics are given for 5-nearest neighbor matching ( 0.03 caliper). 
Table A10b Balance statistics for improved-uninterrupted definition of water: Children residing in urban areas

\begin{tabular}{|c|c|c|c|c|c|}
\hline \multirow[b]{2}{*}{ Variable } & \multirow[b]{2}{*}{ Sample } & \multicolumn{2}{|c|}{ Mean } & \multicolumn{2}{|c|}{ T-test } \\
\hline & & Treated & Control & $\begin{array}{c}\text { T- } \\
\text { stat }\end{array}$ & $\mathbf{p}>|\mathbf{t}|$ \\
\hline \multirow[t]{2}{*}{ Lower Egypt urban } & Unmatched & 0.228 & 0.235 & -0.48 & 0.628 \\
\hline & Matched & 0.229 & 0.228 & 0.11 & 0.911 \\
\hline \multirow[t]{2}{*}{ Upper Egypt urban } & Unmatched & 0.314 & 0.327 & -0.80 & 0.422 \\
\hline & Matched & 0.314 & 0.326 & -0.94 & 0.347 \\
\hline \multirow[t]{2}{*}{ Urban governorates } & Unmatched & 0.419 & 0.215 & 12.70 & 0.000 \\
\hline & Matched & 0.419 & 0.266 & 11.84 & 0.000 \\
\hline \multirow[t]{2}{*}{ Lowest wealth quintile } & Unmatched & 0.040 & 0.102 & -7.65 & 0.000 \\
\hline & Matched & 0.040 & 0.036 & 0.65 & 0.515 \\
\hline \multirow[t]{2}{*}{ Second wealth quintile } & Unmatched & 0.089 & 0.119 & -2.92 & 0.003 \\
\hline & Matched & 0.089 & 0.087 & 0.35 & 0.727 \\
\hline \multirow[t]{2}{*}{ Third wealth quintile } & Unmatched & 0.152 & 0.179 & -2.12 & 0.034 \\
\hline & Matched & 0.153 & 0.141 & 1.23 & 0.219 \\
\hline \multirow[t]{2}{*}{ Fourth wealth quintile } & Unmatched & 0.262 & 0.253 & 0.58 & 0.565 \\
\hline & Matched & 0.262 & 0.270 & -0.70 & 0.486 \\
\hline \multirow[t]{2}{*}{ Mother's education } & Unmatched & 10.181 & 8.701 & 8.44 & 0.000 \\
\hline & Matched & 10.175 & 10.201 & -0.19 & 0.852 \\
\hline \multirow[t]{2}{*}{ Father's education } & Unmatched & 10.681 & 9.572 & 6.44 & 0.000 \\
\hline & Matched & 10.677 & 10.617 & 0.43 & 0.666 \\
\hline \multirow[t]{2}{*}{ Dwelling (house) } & Unmatched & 0.164 & 0.283 & -8.67 & 0.000 \\
\hline & Matched & 0.165 & 0.169 & -0.45 & 0.656 \\
\hline \multirow[t]{2}{*}{ Dwelling (apartment) } & Unmatched & 0.820 & 0.708 & 7.98 & 0.000 \\
\hline & Matched & 0.819 & 0.821 & -0.15 & 0.883 \\
\hline \multirow[t]{2}{*}{ Mother Edu * Father Edu } & Unmatched & 125.500 & 100.530 & 8.50 & 0.000 \\
\hline & Matched & 125.360 & 125.410 & -0.02 & 0.983 \\
\hline
\end{tabular}

Note: Balance statistics are given for 5-nearest neighbor matching ( 0.03 caliper). 


\begin{tabular}{lrrrrrr}
\hline \multicolumn{7}{l}{ Table A11 PSM matching estimates for WHO definition of improved sanitation } \\
\hline & $\begin{array}{l}\text { Mean } \\
\text { Treatment }\end{array}$ & $\begin{array}{l}\text { Mean } \\
\text { Control }\end{array}$ & \multicolumn{1}{c}{ ATT } & \multicolumn{1}{c}{ S.E. } & \multicolumn{1}{c}{ T-stat } \\
Method & 0.092 & 0.102 & -0.010 & 0.009 & -1.08 \\
Naïve estimation & 0.092 & 0.068 & 0.025 & 0.029 & 0.86 \\
One-to-one matching & 0.092 & 0.104 & -0.012 & 0.015 & -0.78 \\
Radius matching & 0.092 & 0.100 & -0.008 & 0.014 & -0.54 \\
Kernel matching & 0.092 & 0.104 & -0.011 & 0.018 & -0.62 \\
LLR matching & 0.092 & 0.087 & 0.006 & 0.019 & 0.30 \\
5 nearest neighbor matching & & & &
\end{tabular}

LLR = Local linear regression.

Notes: Caliper $=0.03$ for all matching methods; 77 treated cases off support.

$\mathrm{N}$ treated $=1,142 ; \mathrm{N}$ control $=9,314$.

Significant at ${ }^{\wedge} \mathrm{p}<.10 ; * \mathrm{p}<.05 ; * * \mathrm{p}<.01 ; * * * \mathrm{p}<.001$. 
Table A12 Balance statistics for WHO definition of improved sanitation

\begin{tabular}{|c|c|c|c|c|c|}
\hline \multirow[b]{3}{*}{ Variable } & & \multicolumn{2}{|c|}{ Mean } & \multicolumn{2}{|c|}{ T-test } \\
\hline & & Treate & & & \\
\hline & Sample & d & Control & T-stat & $\mathbf{p}>|\mathbf{t}|$ \\
\hline \multirow[t]{2}{*}{ Lower Egypt urban } & Unmatched & 0.094 & 0.009 & 9.83 & 0.000 \\
\hline & Matched & 0.087 & 0.113 & -6.05 & 0.000 \\
\hline \multirow[t]{2}{*}{ Lower Egypt rural } & Unmatched & 0.281 & 0.263 & 1.29 & 0.197 \\
\hline & Matched & 0.283 & 0.300 & -2.60 & 0.009 \\
\hline \multirow[t]{2}{*}{ Upper Egypt urban } & Unmatched & 0.122 & 0.068 & 5.46 & 0.000 \\
\hline & Matched & 0.124 & 0.123 & 0.16 & 0.872 \\
\hline \multirow[t]{2}{*}{ Upper Egypt rural } & Unmatched & 0.304 & 0.573 & -18.60 & 0.000 \\
\hline & Matched & 0.306 & 0.303 & 0.39 & 0.693 \\
\hline \multirow[t]{2}{*}{ Frontier governorates } & Unmatched & 0.058 & 0.061 & -0.38 & 0.706 \\
\hline & Matched & 0.058 & 0.043 & 4.81 & 0.000 \\
\hline \multirow[t]{2}{*}{ Lowest wealth quintile } & Unmatched & 0.175 & 0.373 & -16.12 & 0.000 \\
\hline & Matched & 0.177 & 0.190 & -2.34 & 0.019 \\
\hline \multirow[t]{2}{*}{ Second wealth quintile } & Unmatched & 0.187 & 0.276 & -7.17 & 0.000 \\
\hline & Matched & 0.189 & 0.176 & 2.19 & 0.029 \\
\hline \multirow[t]{2}{*}{ Third wealth quintile } & Unmatched & 0.200 & 0.166 & 2.76 & 0.006 \\
\hline & Matched & 0.202 & 0.281 & 12.76 & 0.000 \\
\hline \multirow[t]{2}{*}{ Fourth wealth quintile } & Unmatched & 0.208 & 0.103 & 8.51 & 0.000 \\
\hline & Matched & 0.208 & 0.217 & -1.58 & 0.115 \\
\hline \multirow[t]{2}{*}{ Mother's education } & Unmatched & 7.849 & 4.777 & 17.84 & 0.000 \\
\hline & Matched & 7.788 & 7.383 & 5.07 & 0.000 \\
\hline \multirow[t]{2}{*}{ Father's education } & Unmatched & 9.110 & 6.641 & 14.84 & 0.000 \\
\hline & Matched & 9.053 & 8.751 & 3.96 & 0.000 \\
\hline \multirow[t]{2}{*}{ Dwelling (house) } & Unmatched & 0.454 & 0.568 & -7.30 & 0.000 \\
\hline & Matched & 0.457 & 0.466 & -1.27 & 0.203 \\
\hline \multirow[t]{3}{*}{ Dwelling (apartment) } & Unmatched & 0.539 & 0.324 & 13.86 & 0.000 \\
\hline & Matched & 0.536 & 0.527 & 1.29 & 0.196 \\
\hline & & 1813.2 & 2009.40 & & \\
\hline \multirow[t]{3}{*}{ Household head age (squared) } & Unmatched & 00 & 0 & -5.26 & 0.000 \\
\hline & & 1814.7 & 1988.80 & & \\
\hline & Matched & 00 & 0 & -9.80 & 0.000 \\
\hline
\end{tabular}

Note: Balance statistics are given for 5-nearest neighbor matching (0.03 caliper). 


\section{Figure A.2}

Propensity score distribution:

WHO definition for improved sanitation, before matching

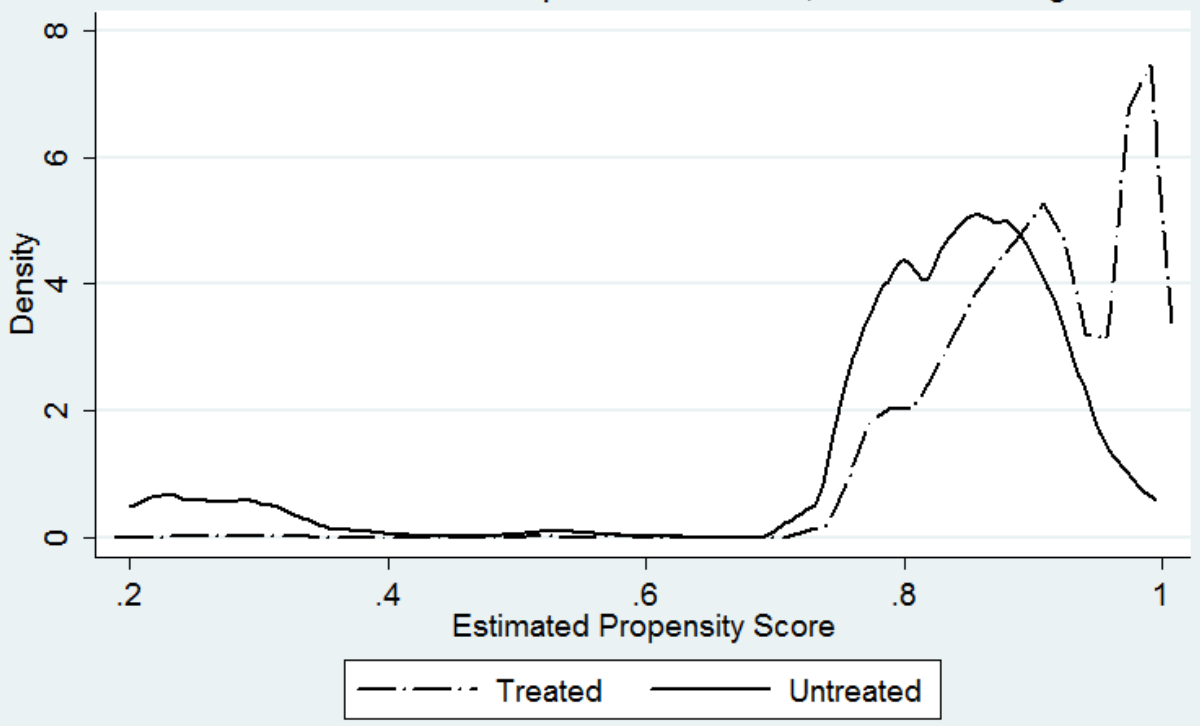

Note:Treatment=Access to improved sanitation facility

Propensity score distribution:

WHO definition for improved sanitation, after matching

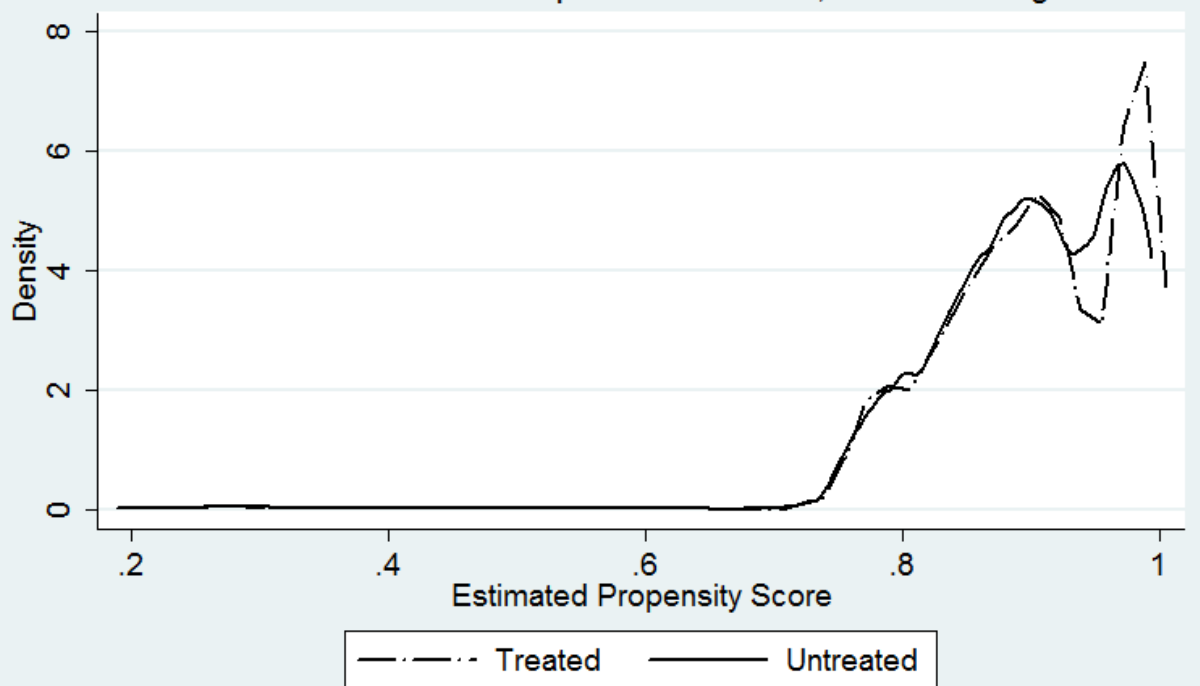

Note: Radius matching (caliper $=0.03$ ); Treatment=Access to improved sanitation facility Source: DHS 2008, Egypt 


\begin{tabular}{|c|c|c|c|c|c|}
\hline \multirow[b]{2}{*}{ Variable } & \multirow[b]{2}{*}{ Sample } & \multicolumn{2}{|c|}{ Mean } & \multicolumn{2}{|c|}{ T-test } \\
\hline & & Treated & Control & T-stat & $\mathbf{p}>|\mathbf{t}|$ \\
\hline \multirow[t]{2}{*}{ Lower Egypt urban } & Unmatched & 0.168 & 0.014 & 29.56 & 0.000 \\
\hline & Matched & 0.169 & 0.195 & -3.20 & 0.001 \\
\hline \multirow[t]{2}{*}{ Lower Egypt rural } & Unmatched & 0.302 & 0.259 & 4.97 & 0.000 \\
\hline & Matched & 0.304 & 0.314 & -0.98 & 0.326 \\
\hline \multirow[t]{2}{*}{ Upper Egypt urban } & Unmatched & 0.164 & 0.076 & 14.16 & 0.000 \\
\hline & Matched & 0.165 & 0.161 & 0.47 & 0.638 \\
\hline \multirow[t]{2}{*}{ Upper Egypt rural } & Unmatched & 0.061 & 0.561 & -64.09 & 0.000 \\
\hline & Matched & 0.061 & 0.063 & -0.40 & 0.690 \\
\hline \multirow[t]{2}{*}{ Frontier governorates } & Unmatched & 0.043 & 0.071 & -6.24 & 0.000 \\
\hline & Matched & 0.042 & 0.035 & 1.98 & 0.048 \\
\hline \multirow[t]{2}{*}{ Lowest wealth quintile } & Unmatched & 0.063 & 0.309 & -33.37 & 0.000 \\
\hline & Matched & 0.063 & 0.067 & -0.83 & 0.408 \\
\hline \multirow[t]{2}{*}{ Second wealth quintile } & Unmatched & 0.116 & 0.264 & -19.35 & 0.000 \\
\hline & Matched & 0.117 & 0.115 & 0.39 & 0.697 \\
\hline \multirow[t]{2}{*}{ Third wealth quintile } & Unmatched & 0.182 & 0.209 & -3.40 & 0.001 \\
\hline & Matched & 0.183 & 0.175 & 1.03 & 0.301 \\
\hline \multirow[t]{2}{*}{ Fourth wealth quintile } & Unmatched & 0.267 & 0.138 & 16.86 & 0.000 \\
\hline & Matched & 0.268 & 0.270 & -0.25 & 0.800 \\
\hline \multirow[t]{2}{*}{ Mother's education } & Unmatched & 9.752 & 5.641 & 40.40 & 0.000 \\
\hline & Matched & 9.716 & 9.573 & 1.40 & 0.162 \\
\hline \multirow[t]{2}{*}{ Father's education } & Unmatched & 10.190 & 7.711 & 24.28 & 0.000 \\
\hline & Matched & 10.158 & 9.928 & 2.23 & 0.026 \\
\hline \multirow[t]{2}{*}{ Dwelling (house) } & Unmatched & 0.231 & 0.664 & -49.25 & 0.000 \\
\hline & Matched & 0.233 & 0.224 & 1.00 & 0.316 \\
\hline \multirow[t]{2}{*}{ Dwelling (apartment) } & Unmatched & 0.763 & 0.308 & 52.30 & 0.000 \\
\hline & Matched & 0.761 & 0.770 & -1.05 & 0.316 \\
\hline \multirow[t]{2}{*}{ Dwelling (urban apartment) } & Unmatched & 0.552 & 0.064 & 65.51 & 0.000 \\
\hline & Matched & 0.549 & 0.549 & 0.06 & 0.954 \\
\hline \multirow[t]{2}{*}{ Mother's edu * father's edu } & Unmatched & 116.160 & 60.561 & 36.81 & 0.000 \\
\hline & Matched & 115.310 & 112.150 & 1.89 & 0.059 \\
\hline \multirow[t]{2}{*}{ Rural } & Unmatched & 0.368 & 0.858 & -60.47 & 0.000 \\
\hline & Matched & 0.370 & 0.381 & -1.09 & 0.276 \\
\hline \multirow[t]{2}{*}{ Upper Egypt rural poor } & Unmatched & 0.026 & 0.387 & -49.38 & 0.000 \\
\hline & Matched & 0.026 & 0.026 & 0.04 & 0.969 \\
\hline \multirow[t]{2}{*}{ Lower Egypt rural poor } & Unmatched & 0.088 & 0.105 & -2.91 & 0.004 \\
\hline & Matched & 0.089 & 0.092 & -0.46 & 0.643 \\
\hline
\end{tabular}

Note: Balance statistics are given for 5-nearest neighbor matching (0.03 caliper). 
Table A14 Balance statistics for no septic tank or bayara (treatment) versus septic tank or bayara in the DHS enumeration area

\begin{tabular}{|c|c|c|c|c|c|}
\hline \multirow[b]{2}{*}{ Variable } & \multirow[b]{2}{*}{ Sample } & \multicolumn{2}{|c|}{ Mean } & \multicolumn{2}{|c|}{ T-test } \\
\hline & & Treated & Control & T-stat & $\mathbf{p}>|\mathbf{t}|$ \\
\hline \multirow[t]{2}{*}{ Lower Egypt urban } & Unmatched & 0.193 & 0.085 & 8.51 & 0.000 \\
\hline & Matched & 0.206 & 0.201 & 0.51 & 0.609 \\
\hline \multirow[t]{2}{*}{ Lower Egypt rural } & Unmatched & 0.257 & 0.455 & -12.79 & 0.000 \\
\hline & Matched & 0.275 & 0.279 & -0.44 & 0.657 \\
\hline \multirow[t]{2}{*}{ Upper Egypt urban } & Unmatched & 0.153 & 0.202 & -3.82 & 0.000 \\
\hline & Matched & 0.162 & 0.170 & -0.89 & 0.375 \\
\hline \multirow[t]{2}{*}{ Upper Egypt rural } & Unmatched & 0.024 & 0.186 & -20.72 & 0.000 \\
\hline & Matched & 0.025 & 0.024 & 0.15 & 0.877 \\
\hline \multirow[t]{2}{*}{ Frontier governorates } & Unmatched & 0.040 & 0.053 & -1.83 & 0.067 \\
\hline & Matched & 0.042 & 0.042 & 0.04 & 0.971 \\
\hline \multirow[t]{2}{*}{ Lowest wealth quintile } & Unmatched & 0.035 & 0.156 & -14.89 & 0.000 \\
\hline & Matched & 0.038 & 0.034 & 0.73 & 0.463 \\
\hline \multirow[t]{2}{*}{ Second wealth quintile } & Unmatched & 0.096 & 0.185 & -8.10 & 0.000 \\
\hline & Matched & 0.103 & 0.097 & 0.85 & 0.397 \\
\hline \multirow[t]{2}{*}{ Third wealth quintile } & Unmatched & 0.165 & 0.242 & -5.83 & 0.000 \\
\hline & Matched & 0.175 & 0.167 & 0.90 & 0.370 \\
\hline \multirow[t]{2}{*}{ Fourth wealth quintile } & Unmatched & 0.277 & 0.231 & 3.06 & 0.002 \\
\hline & Matched & 0.293 & 0.315 & -2.06 & 0.040 \\
\hline \multirow[t]{2}{*}{ Mother's education } & Unmatched & 10.211 & 8.192 & 11.98 & 0.000 \\
\hline & Matched & 10.099 & 9.471 & 5.49 & 0.000 \\
\hline \multirow[t]{2}{*}{ Father's education } & Unmatched & 10.478 & 9.214 & 7.37 & 0.000 \\
\hline & Matched & 10.549 & 10.148 & 3.37 & 0.001 \\
\hline \multirow[t]{2}{*}{ Dwelling (house) } & Unmatched & 0.172 & 0.434 & -18.75 & 0.000 \\
\hline & Matched & 0.183 & 0.184 & -0.09 & 0.926 \\
\hline \multirow[t]{2}{*}{ Dwelling (apartment) } & Unmatched & 0.822 & 0.563 & 18.37 & 0.000 \\
\hline & Matched & 0.811 & 0.804 & 0.77 & 0.444 \\
\hline \multirow[t]{2}{*}{ Rural Poor } & Unmatched & 0.081 & 0.235 & -14.25 & 0.000 \\
\hline & Matched & 0.087 & 0.089 & -0.30 & 0.761 \\
\hline \multirow[t]{2}{*}{ Dwelling (rural house) } & Unmatched & 0.107 & 0.321 & -17.76 & 0.000 \\
\hline & Matched & 0.114 & 0.116 & -0.20 & 0.845 \\
\hline \multirow[t]{2}{*}{ Dwelling (urban apartment) } & Unmatched & 0.647 & 0.231 & 26.00 & 0.000 \\
\hline & Matched & 0.625 & 0.613 & 1.03 & 0.303 \\
\hline \multirow[t]{2}{*}{ Upper Egypt rural poor } & Unmatched & 0.007 & 0.090 & -15.61 & 0.000 \\
\hline & Matched & 0.007 & 0.007 & 0.25 & 0.799 \\
\hline
\end{tabular}

Note: Balance statistics are given for 5-nearest neighbor matching ( 0.03 caliper). 
Table A15 Balance statistics for improved-connected definition for sanitation: Mothers with 0 years of education

\begin{tabular}{|c|c|c|c|c|c|}
\hline \multirow[b]{2}{*}{ Variable } & \multirow[b]{2}{*}{ Sample } & \multicolumn{2}{|c|}{ Mean } & \multicolumn{2}{|c|}{ T-test } \\
\hline & & Treated & Control & T-stat & $\mathbf{p}>|\mathbf{t}|$ \\
\hline \multirow[t]{2}{*}{ Lower Egypt urban } & Unmatched & 0.073 & 0.003 & 12.32 & 0.000 \\
\hline & Matched & 0.074 & 0.067 & 0.50 & 0.619 \\
\hline \multirow[t]{2}{*}{ Lower Egypt rural } & Unmatched & 0.345 & 0.160 & 10.66 & 0.000 \\
\hline & Matched & 0.347 & 0.370 & -0.87 & 0.387 \\
\hline \multirow[t]{2}{*}{ Upper Egypt urban } & Unmatched & 0.147 & 0.070 & 6.23 & 0.000 \\
\hline & Matched & 0.147 & 0.153 & -0.27 & 0.786 \\
\hline \multirow[t]{2}{*}{ Upper Egypt rural } & Unmatched & 0.191 & 0.668 & -23.71 & 0.000 \\
\hline & Matched & 0.190 & 0.185 & 0.24 & 0.810 \\
\hline \multirow[t]{2}{*}{ Frontier governorates } & Unmatched & 0.044 & 0.083 & -3.36 & 0.001 \\
\hline & Matched & 0.041 & 0.040 & 0.08 & 0.933 \\
\hline \multirow[t]{2}{*}{ Lowest wealth quintile } & Unmatched & 0.264 & 0.500 & -10.92 & 0.000 \\
\hline & Matched & 0.262 & 0.263 & -0.03 & 0.980 \\
\hline \multirow[t]{2}{*}{ Second wealth quintile } & Unmatched & 0.263 & 0.283 & -1.05 & 0.296 \\
\hline & Matched & 0.264 & 0.240 & 1.00 & 0.317 \\
\hline \multirow[t]{2}{*}{ Third wealth quintile } & Unmatched & 0.200 & 0.144 & 3.46 & 0.001 \\
\hline & Matched & 0.201 & 0.226 & -1.11 & 0.266 \\
\hline \multirow[t]{2}{*}{ Fourth wealth quintile } & Unmatched & 0.195 & 0.048 & 12.55 & 0.000 \\
\hline & Matched & 0.195 & 0.220 & -1.11 & 0.269 \\
\hline \multirow[t]{2}{*}{ Father's education } & Unmatched & 4.286 & 4.553 & -1.26 & 0.207 \\
\hline & Matched & 4.276 & 3.704 & 2.35 & 0.019 \\
\hline \multirow[t]{2}{*}{ Dwelling (house) } & Unmatched & 0.490 & 0.773 & -14.62 & 0.000 \\
\hline & Matched & 0.489 & 0.514 & -0.90 & 0.367 \\
\hline \multirow[t]{2}{*}{ Dwelling (apartment) } & Unmatched & 0.179 & 0.487 & 16.88 & 0.000 \\
\hline & Matched & 0.488 & 0.470 & 0.64 & 0.524 \\
\hline \multirow[t]{2}{*}{ Lower Egypt rural poor } & Unmatched & 0.231 & 0.103 & 8.62 & 0.000 \\
\hline & Matched & 0.232 & 0.246 & -0.61 & 0.542 \\
\hline \multirow[t]{2}{*}{ Rural } & Unmatched & 0.553 & 0.884 & -20.47 & 0.000 \\
\hline & Matched & 0.554 & 0.571 & -0.64 & 0.525 \\
\hline \multirow[t]{2}{*}{ Dwelling (urban apartment) } & Unmatched & 0.318 & 0.032 & 24.12 & 0.000 \\
\hline & Matched & 0.319 & 0.302 & 0.68 & 0.499 \\
\hline \multirow[t]{2}{*}{ Mother employed } & Unmatched & 0.072 & 0.076 & -0.35 & 0.726 \\
\hline & Matched & 0.072 & 0.044 & 2.16 & 0.031 \\
\hline
\end{tabular}

Note: Balance statistics are given for 5-nearest neighbor matching ( 0.03 caliper). 
Table A16a: Balance statistics for improved-connected definition for sanitation: Children residing in rural areas

\begin{tabular}{llrrrr}
\hline & & \multicolumn{2}{c}{ Mean } & \multicolumn{2}{c}{ T-test } \\
\hline Variable & Sample & Treated & Control & T-stat & $\mathbf{p}>|\mathbf{t}|$ \\
\hline Lower Egypt rural & Unmatched & 0.822 & 0.302 & 42.73 & 0.000 \\
& Matched & 0.823 & 0.821 & 0.11 & 0.916 \\
Upper Egypt rural & Unmatched & 0.165 & 0.654 & 39.21 & 0.000 \\
& Matched & 0.165 & 0.168 & -0.24 & 0.808 \\
Frontier governorates & Unmatched & 0.012 & 0.044 & -6.17 & 0.000 \\
& Matched & 0.012 & 0.011 & 0.47 & 0.638 \\
Lowest wealth quintile & & & & - & \\
& Unmatched & 0.123 & 0.330 & 17.14 & 0.000 \\
Second wealth quintile & Matched & 0.123 & 0.120 & 0.30 & 0.766 \\
& Unmatched & 0.193 & 0.275 & -6.81 & 0.000 \\
Third wealth quintile & Matched & 0.193 & 0.193 & 0.03 & 0.973 \\
& Unmatched & 0.251 & 0.205 & 4.05 & 0.000 \\
Fourth wealth quintile & Matched & 0.251 & 0.248 & 0.22 & 0.828 \\
& Unmatched & 0.256 & 0.126 & 13.00 & 0.000 \\
Mother's education & Matched & 0.257 & 0.261 & -0.28 & 0.782 \\
& Unmatched & 8.450 & 5.467 & 20.35 & 0.000 \\
Father's education & Matched & 8.446 & 8.285 & 0.93 & 0.354 \\
& Unmatched & 8.986 & 7.628 & 9.18 & 0.000 \\
Dwelling (house) & Matched & 8.995 & 9.084 & -0.51 & 0.608 \\
& Unmatched & 0.573 & 0.284 & 22.54 & 0.000 \\
Dwelling (apartment) & Matched & 0.572 & 0.580 & -0.49 & 0.624 \\
& Unmatched & 0.423 & 0.690 & 20.40 & 0.000 \\
& Matched & 0.424 & 0.418 & 0.38 & 0.703 \\
\hline & & & &
\end{tabular}

Note: Balance statistics are given for 5-nearest neighbor matching (0.03 caliper). 
Table A16b Balance statistics for improved-connected definition for sanitation: Children residing in urban areas

\begin{tabular}{llrrrr}
\hline & & \multicolumn{2}{c}{ Mean } & \multicolumn{2}{c}{ T-test } \\
\hline Variable & Sample & Treated & Control & T-stat & $\mathbf{p}>|\mathbf{t}|$ \\
\hline Lower Egypt urban & Unmatched & 0.266 & 0.099 & 10.22 & 0.000 \\
& Matched & 0.270 & 0.309 & -3.32 & 0.001 \\
Upper Egypt urban & Unmatched & 0.260 & 0.537 & -15.59 & 0.000 \\
Urban governorates & Matched & 0.263 & 0.215 & 4.37 & 0.000 \\
& Unmatched & 0.414 & 0.127 & 15.71 & 0.000 \\
Lowest wealth quintile & Matched & 0.407 & 0.363 & 3.46 & 0.001 \\
& Unmatched & 0.028 & 0.181 & -16.92 & 0.000 \\
Second wealth quintile & Matched & 0.028 & 0.031 & -0.61 & 0.541 \\
Third wealth quintile & Unmatched & 0.072 & 0.199 & -11.01 & 0.000 \\
& Matched & 0.073 & 0.076 & -0.37 & 0.708 \\
Fourth wealth quintile & Unmatched & 0.142 & 0.230 & -6.07 & 0.000 \\
Mother's education & Matched & 0.144 & 0.122 & 2.53 & 0.012 \\
& Unmatched & 0.273 & 0.208 & 3.78 & 0.000 \\
Father's education & Matched & 0.276 & 0.281 & -0.45 & 0.653 \\
Dwelling (house) & Unmatched & 10.510 & 6.694 & 19.75 & 0.000 \\
Dwelling (apartment) & Matched & 10.425 & 10.723 & -2.52 & 0.012 \\
& Unmatched & 10.890 & 8.210 & 13.85 & 0.000 \\
\hline Matched & 10.817 & 10.624 & 1.57 & 0.116 \\
& Unmatched & 0.873 & 0.451 & 28.72 & 0.000 \\
& Matched & 0.871 & 0.863 & 0.90 & 0.366 \\
& Unmatched & 0.120 & 0.510 & -26.92 & 0.000 \\
& Matched & 0.122 & 0.128 & -0.77 & 0.444 \\
\hline
\end{tabular}

Note: Balance statistics are given for 5-nearest neighbor matching ( 0.03 caliper). 


\section{Appendix 2 \\ Interview and Focus Group Discussion Questions}

\section{Questions for Households}

\section{General Information}

1. Number of household members (age, education).

2. Did any member of the household suffer from cholera, diarrhea, diphtheria, dysentery, eye infections, skin rashes, or typhoid?

3. If yes,

a) Who were these household members?

b) Did they catch these diseases before the household became connected to the new water/sanitation service?

c) How was the disease treated? Did you try any of the following: taking ORS, zinc treatment, hand washing, proper breastfeeding, taking fluids, taking Vitamin A supplements, taking vaccines for the Rota virus?

d) Did you go to the public health clinic at the village?

4. What do you think are the main causes of childhood diarrhea and the other diseases mentioned?

5. (On-site observation) Is there running water in the house? Is the water pressure good?

6. (On-site observation) Is the latrine clean? Does it function well?

7. (On-site observation) What is the hygienic state of the house and the children?

\section{Drinking Water Services}

1. When did the household become connected to the piped network?

2. How did you get this connection (through the water company, a project, etc.)?

3. How much did you pay for the connection?

\section{Situation Before Improved Water Services}

1. How did you get drinking water before?

2. Who was responsible for fetching the water and how many times was this done during the day?

3. Was the quality of the water acceptable? If not, why not? 
4. For what purposes did you use the water in your daily life (washing, caring for children, and so on)?

5. Did you ever need to store water? If so, where was it stored and how?

6. In general, did you have any problems with the drinking-water services available?

\section{Situation After Improved Water Services}

1. Do you feel your situation has improved or is it still the same? If "Yes, it has improved," explain. If "No," why not?

2. Are you satisfied with the quantity and quality of the drinking water in your house?

3. Do you still need to store water? If "Yes," why?

4. If you have problems with the current system, what did you do to try to solve them?

5. Did you change anything in the way you perform your daily washing duties-particularly with respect to your children - after the improved system was installed in your home (such as frequency of bathing, hand/face washing, cleaning of cooking utensils, washing of clothes)?

\section{Sanitation Services}

1. When did the household become connected to the piped network?

2. How did you get this connection (through the water company, a project, etc.)?

3. How much did you pay for the connection?

\section{Situation Before Improved Services}

1. Did you have a latrine? If "Yes," how many times did you evacuate your septic tank and at what cost?

2. If you did not have a latrine, what was your alternative?

3. Did you have any problems with your septic tank or with the system as a whole? If "Yes," explain.

\section{Situation After Improved Services}

1. Do you feel your situation has improved or is it still the same? If "Yes, it has improved," explain. If "No," why not?

2. If you have problems with the current system, what did you do to try to solve them?

3. Did you change anything in the way you perform your daily washing duties - particularly with respect to your children - after the improved system was installed in your home? 


\section{Questions for Health Clinic Staff}

1. What are the most frequent diseases in general in the village, and what is their intensity?

2. What are the most frequent waterborne diseases in the village, and what is their intensity?

3. Did you notice a change in the frequency of waterborne diseases after the introduction of improved water/sanitation services in the village?

4. Do you think these diseases - especially diarrhea - are related to the use of water and sanitation services by residents?

5. Do you know of any infants/children who have died as a result of diarrhea or other waterborne diseases? If "Yes," how many and when?

6. Who are the greatest victims of these diseases?

7. Who are the most frequent visitors to the health clinic?

8. Did the clinic undertake any awareness-raising activities related to hygiene, diarrhea, and child health in general? If "Yes," what was their nature, duration, and frequency, and what awareness messages were communicated?

9. Does the clinic suffer from problems of shortage of doctors, medication, and similar limitations? How do these problems affect the treatment by the clinic of the above-mentioned diseases?

10. Do you know of the Rota virus? Do you provide immunization for it? 


\section{Questions for School Officials}

1. General information: date of establishment, number of students, teachers, administrators, and workers.

2. Do the students suffer from diarrhea and other waterborne diseases? If "Yes," what is the frequency and which ages are most affected?

3. Do you think the incidence of diarrhea is related to the use of water/sanitation services by the residents?

4. Does the school have an adequate and clean drinking-water service? If not, what are the problems?

5. Does the school have an adequate and hygienic sanitation system? If not, what are the problems?

6. If there are problems, what steps has the school taken to address them?

7. Has the school undertaken any awareness-raising activities on diarrhea, hygiene, and child health in general? If "Yes," what was their nature, duration, and frequency, and what awareness messages were communicated?

8. Do you think these activities had a positive impact on changing the students' hygiene behaviors? If not, why not?

9. What challenges does the school face when trying to implement awareness-raising activities? 


\section{Recent Poverty, Gender, and Youth Working Papers}

Working papers are distributed electronically. When a new paper is published, subscribers are notified by e-mail and a link to the paper is provided.

To subscribe to the Poverty, Gender, and Youth working paper e-mail notification list, please send your request to pgywp@popcouncil.org.

PDFs of working papers are available at www.popcouncil.org/publications/wp.asp

2012

24 Rania Roushdy, Maia Sieverding, and Hana Radwan, "The impact of water supply and sanitation on child health: Evidence from Egypt."

2011

23 Judith Bruce, Nicole Haberland, Amy Joyce, Eva Roca, and Tobey Nelson Sapriano, "First generation of gender and HIV programs: Seeking clarity and synergy."

22 Ghada Barsoum, Nadia Rifaat, Omaima El-Gibaly, Nihal Elwan, and Natalie Foricer, "National efforts toward FGM-free villages in Egypt: The evidence of impact."

2010

21 Ashish Bajracharya, "The nature of mothers' work and children's schooling in Nepal: The influence of income and time effects."

20 John Bongaarts, "The causes of educational differences in fertility in sub-Saharan Africa."

19 Ashish Bajracharya and Sajeda Amin, "Poverty, marriage timing, and transitions to adulthood in Nepal: A longitudinal analysis using the Nepal Living Standards Survey."

\section{9}

18 Sajeda Amin and Bussarawan Teerawichitchainan, "Ethnic fertility differentials in Vietnam and their proximate determinants."

17 Sajeda Amin and S. Chandrasekhar, "Looking beyond universal primary education: Gender differences in time use among children in rural Bangladesh."

16 John Bongaarts, François Pelletier, and Patrick Gerland, "Global trends in AIDS mortality."

15 Bussarawan Teerawichitchainan and Sajeda Amin, "The role of abortion in the last stage of fertility decline in Vietnam."

14 Cynthia B. Lloyd and Paul C. Hewett, "Educational inequalities in the midst of persistent poverty: Diversity across Africa in educational outcomes."

13 Wendy Baldwin and Judith Diers, "Demographic data for development in sub-Saharan Africa." 
2008

12 Sajeda Amin and Lopita Huq, "Marriage considerations in sending girls to school in Bangladesh: Some qualitative evidence."

11 S. Chandrasekhar and Abhiroop Mukhopadhyay, "Multiple dimensions of urban well-being: Evidence from India"

10 Sajeda Amin and Luciana Suran, "Terms of marriage and time-use patterns of young wives: Evidence from rural Bangladesh."

9 John Bongaarts, Thomas Buettner, Gerhard Heilig, and François Pelletier, "Has the HIV epidemic peaked?"

8 Barbara S. Mensch, Paul C. Hewett, Richard Gregory, and Stephane Helleringer, "Sexual behavior and STI/HIV status among adolescents in rural Malawi: An evaluation of the effect of interview mode on reporting."

7 John Bongaarts, "Fertility transitions in developing countries: Progress or stagnation?" 